\title{
Preventive Maintenance Strategy for Train Doors Based on the Competitive Weibull Theory
}

deqiang he

Guangxi University https://orcid.org/0000-0002-7668-9399

Xiaozhen Zhang

Guangxi University

Yanjun Chen

Guangxi Uniersity

Jian Miao ( $\nabla 115108084 @ q q . c o m)$

Congbo Li

Chongqing University

Xiaoyang Yao

CRRC Zhuzhou Institute Co., Ltd.

Original Article

Keywords: Competitive Weibull, Fault Information Sequence, Train Door, Fuzzy Cluster, Preventive Maintenance

Posted Date: May 11th, 2020

DOI: https://doi.org/10.21203/rs.3.rs-27291/v1

License: (c) (1) This work is licensed under a Creative Commons Attribution 4.0 International License.

Read Full License 


\title{
Preventive Maintenance Strategy for Train Doors Based on the Competitive Weibull Theory
}

\author{
Deqiang $\mathrm{He}^{1}$, Xiaozhen Zhang ${ }^{1}$, Yanjun Chen ${ }^{1}$, Jian Miao ${ }^{1, *}$, Congbo $\mathrm{Li}^{2}$, Xiaoyang $\mathrm{Yao}^{3}$
}

\begin{abstract}
In view of the problems of over-maintenance and under-maintenance in the current urban rail transit maintenance strategy and the reliability of single processing of fault data, which is often inconsistent with the actual situation, an incomplete preventive maintenance strategy based on the competitive Weibull model is proposed in this paper. To make the fault mechanism processing method for urban rail vehicles more accurate, fault feature attributes and fault information sequences are introduced to classify fault data. Fuzzy cluster analysis of vehicle fault data can be performed using the formula of the competitive Weibull model, and parameter estimation of the reliability model can be performed by combining it with the graph parameter estimation method. In addition, the fault rate increase factor and service age reduction factor are introduced into the maintenance strategy, and the optimal preventive maintenance cycle and maintenance times are obtained by combining maintenance and replacement according to reliability. A quantum-genetic intelligent algorithm is used to optimize the model-solving process. Finally, the maintenance of urban rail transit train doors is taken as an example. The results of this study show that compared with the traditional maintenance strategy, the reliability of the proposed maintenance strategy is closer to the actual situation. At the same time, the proposed maintenance strategy can effectively reduce the number of parked vehicles, reduce maintenance costs, and ensure the safety of train operation, maintenance economy and performance of tasks.
\end{abstract}

Keywords: Competitive Weibull, Fault Information Sequence, Train Door, Fuzzy Cluster, Preventive Maintenance

\section{Introduction}

In recent years, along with the development of the economy, urban rail transit also has been continuously developing. Research on the safety and economy of rail vehicles is an important part of the urban rail transit system and has far-reaching significance. In addition, the maintenance of rail vehicles is important [1]. According to statistics, the cost of

1 Guangxi Key Laboratory of Manufacturing System and Advanced Manufacturing Technology, School of Mechanical Engineering, Guangxi University, Nanning, 530004, PR China

2 State Key Laboratory of Mechanical Transmission, Chongqing University, Chongqing, 400044, PR China

${ }^{3}$ CRRC Zhuzhou Institute Co., Ltd., Zhuzhou, 400044, PR China

* Corresponding author: Jian Miao (e-mail: 115108084@qq.com) vehicle maintenance accounts for approximately $40 \%$ of the total cost of subway maintenance [2]. Therefore, on the premise of ensuring train safety and the performance of tasks, reducing the cost of vehicle maintenance has become an important research topic in recent years.

At present, the main maintenance modes of metro vehicles are fault maintenance and periodic maintenance, in which the maintenance effect is considered to be complete maintenance, that is, "repair as new". However, this situation is not in line with the actual situation. Maintenance cannot restore the reliability of the system to a completely new state. Therefore, this maintenance mode will cause problems, such as over-maintenance or under-maintenance, which will lead to an increase in maintenance costs and the waste of maintenance resources. In recent years, many scholars have actively explored the reliability-centered maintenance mode. At present, many studies on reliability are based on the single Weibull model, but for complex repairable systems, fault data are often independent and identically distributed [3], which means that the single Weibull model is not suitable for metro vehicles. A metro vehicle is a complex of electromechanical equipment [4], so many kinds of failure mechanisms coexist in the vehicle system, which means that competitive failure objectively exists. For metro vehicles with multiple failure mechanisms, a reliability evaluation can be performed by the hybrid Weibull model and competitive Weibull model. The competitive Weibull model and parameter estimation are mentioned in the literature [5]. A competitive failure model is used to evaluate the reliability of a product in literatures[6][7]. The competitive failure model for specific failure modes or processes has been established in literatures [8][9][10]. Fault data of metro vehicles are used in this paper, and the reliability of rail transit vehicles is solved based on the competitive Weibull model, which compensates for the disadvantage of single fault mechanism processing.

In the reliability-centered maintenance strategy, the maintenance effect mainly includes complete maintenance (repair as new), incomplete maintenance and minimum maintenance (repair as old) [11]. Because the effect of incomplete maintenance is between that of complete maintenance and that of minimum maintenance, it is more suitable for engineering practice and has become an important issue in current maintenance modeling research [12]. Incomplete maintenance is usually expressed by the service age reduction factor and fault rate increase factor. The service age regression factor and failure rate increment factor were 
improved by N. Kuboki [13] and Ronald M. Martinod [14]. At the same time, aiming at preventive maintenance, the nonlinear optimization preventive maintenance strategy was proposed by these authors according to the functional relationship between the failure rate and preventive maintenance interval. The new virtual service age method was introduced by Nguyen D T et al. [15], the maintenance mode of incomplete maintenance was constructed by the new virtual service age method, and three modes of dynamic, static and fault limitation were considered. The preventive maintenance interval optimization model under the condition of maximum availability was established by Shen Guixiang [16] and Wang Lingzhi [17].For various types of repairable equipment, R. Mullo [18] et al. used different methods to combine the occurrence of uncertain types of fault with maintenance and to determine different maintenance intervals for different parts. A variety of new nonlinear selective maintenance optimization methods have been introduced by A. Khatab [19] and Byczanski [20] to construct relevant parameters. Two equivalent models of geometric age regression, GRA and GRI, were proposed by Laurent Doyen [21], and data validation was carried out. Incomplete maintenance was described from another perspective. Therefore, incomplete maintenance has been introduced into practical engineering, and the theoretical model established is more practical.

In addition, clustering [22][23][24] is one of the most widely used techniques in data preprocessing. In general, clustering uses a distance-based [23] or model-based [25] method. An integrated clustering method based on multistage learning was proposed by Indrajit Saha [26] and F. Liang [27], and classification work without attribute value data was also solved. The fuzzy clustering model of multi-attribute data was proposed by Pierpaolo D'Urso [28][29][30], G. Peters [31] and A. Foss[32]. The different measures of each attribute are combined using a weighting scheme so fuzzy clustering analysis of multi-attribute data can be performed. In the absence of a quantitative probability model, fuzzy logic considering field data and expert opinions was proposed by Maryam Gallab [33] and K. Antosz [34], and the classification and evaluation of key risks could be completed. A new type of multicriteria decision making (MCDM) was proposed by Soumava Boral [35], that is, the fuzzy analytic hierarchy process (FAHP) and improved fuzzy multi-attribute ideal comparative analysis (FMAIRCA) were combined to improve the robustness of fault evaluation. Therefore, in this paper, when historical data with various fault types are preprocessed, fuzzy clustering analysis is used to improve the feasibility, and the data obtained at the same time are more in line with those from actual engineering.

The reliability model for key systems of metro vehicles based on the competitive Weibull model was adopted in this paper. The influence of fault types on reliability was considered, and fuzzy clustering analysis of the fault information sequence and fault data was performed to classify fault data, and its reliability was more suitable for engineering practice. The incomplete preventive maintenance model based on the competitive Weibull theory was established, in which the service age reduction factor and the fault rate increased factor were introduced, and the maintenance mode combining incomplete preventive maintenance, fault maintenance and preventive replacement was adopted. At the same time, reliability was constrained and the preventive maintenance threshold was taken as decision variable. The minimum cost per unit time was taken as the objective function. Finally, the goal of improving the availability of metro trains and reducing the total maintenance cost was achieved by the model.

The remainder of this paper is organized as follows. In Section 2, an incomplete preventive maintenance strategy based on the competitive Weibull theory is introduced. In Section 3, the pretreatment of fault data is presented in detail. In Section 4, the solution of the model is presented in detail. A numerical example is provided in Section 5. Conclusions are drawn in Section 6.

\section{Incomplete preventive maintenance strategy based on the competitive Weibull Theory}

This paper adopts the competitive Weibull model. The core of the competitive Weibull theory is to classify fault data. Different fault mechanisms have different effects on reliability. Assuming that system $L$ has $k$ fault mechanisms and that $F_{i}(t)$ is a cumulative failure distribution function, the cumulative failure distribution function of system $L$ is:

$$
F(t)=1-\prod_{i=1}^{k}\left[1-F_{i}(t)\right]
$$

According to the competitive Weibull model, the failure rate of system $L$ can be obtained as follows:

$$
\lambda_{L}=\lambda_{1}+\lambda_{2}+\mathrm{L}+\lambda_{k}(j=1,2,3 \mathrm{~L} k)
$$

The reliability of system $L$ is:

$$
R_{L}=R_{1} \times R_{2} \times \mathrm{L} \times R_{K}=\prod_{j=1}^{k} R_{i}
$$

Incomplete preventive maintenance is then introduced, and the service age reduction factor $a$ and fault rate increase factor $b$ are added. Set $T$ as the incomplete preventive maintenance cycle of system $L$ and $N$ as the total number of incomplete preventive maintenance. Replace the system $L$, that is, complete a maintenance cycle. The $N$-th maintenance replaces system $L$, that is, completes a maintenance cycle. The recurrence formula of the failure rate of incomplete preventive maintenance is as follows:

$$
\begin{gathered}
T=T_{1}+T_{2}+\mathrm{L}+T_{N} \\
\lambda_{i+1}(t)=b_{i} \lambda\left(t+a_{i} T_{i}\right) \quad(i=1,2,3 \mathrm{~L} N)
\end{gathered}
$$

Finally, the reliability of the incomplete preventive maintenance system $L$ based on the competitive Weibull model is obtained:

$$
\begin{aligned}
& R_{L}=R_{1} \times R_{2} \times \mathrm{L} \times R_{K}= \\
& \prod_{j=1}^{k} R_{i}=\exp \left[-\int_{0}^{t} \sum_{j=1}^{k}\left(\prod_{i=1}^{N} b_{i}\right) \lambda\left(t+a_{i} \sum_{i=1}^{N} T_{i}\right) d t\right]
\end{aligned}
$$


In this paper, the objective function is the maintenance cost per unit time of system $L$ :

$$
C_{\text {total }}=C_{m}+C_{p}+C_{r}+C_{d}
$$

where $C_{\text {total }}$ is the total cost of system $L$ maintenance, $C_{m}$ is the cost of a minor fault maintenance, $C_{p}$ is the cost of incomplete preventive maintenance, $C_{r}$ is the replacement cost of system $L$, and $C_{d}$ is the cost of shutdown loss. The cost $C_{m r}$ of a minor fault maintenance for each failure and $C_{r}$ are fixed values. The number of minor fault maintenances can be expressed by the cumulative failure rate in the maintenance interval. The total number of failures is equal to the sum of the cumulative failure rate in each preventive maintenance cycle.

$$
\begin{aligned}
& C_{\min }=\sum_{i=1}^{N} C_{m r} \times n_{i}= \\
& C_{m r} \times\left(\int_{0}^{T_{1}} \sum_{j=1}^{k} \lambda_{1 j}(t) d t+\mathrm{L}+\int_{0}^{T_{n}} \sum_{j=1}^{k} \lambda_{n j}(t) d t\right)
\end{aligned}
$$

This paper divides preventive maintenance costs into two parts. One part is fixed and the other is variable. The cost of a single preventive maintenance interval is as follows:

$$
C_{i}^{p}=C_{i}^{f}+C_{i}^{v}\left(x_{i}, u_{i}, \text { age }\right)
$$

where $x_{i}$ is the degree of retirement of service age, $u_{i}$ is the time required for maintenance, and age is the service time of the system. This equation can be simplified to:

$$
C_{i}^{p}=C_{i}^{f}+i C_{i}^{v}
$$

where $C_{p}$ is the total cost of incomplete preventive maintenance:

$$
\begin{aligned}
& C_{p}=\sum_{i=1}^{N} C_{i}^{p}=\sum_{i=1}^{N}\left(C_{i}^{f}+i C_{i}^{v}\right) \\
& =N C_{f}+\frac{N(N+1)}{2} C_{v}
\end{aligned}
$$

where $C_{d}$ is the cost of shutdown and $C_{d i}$ is the cost of shutdown per unit time:

$$
C_{d}=C_{d i}\left\{\tau_{m} \sum_{n=1}^{N} \int_{0}^{T_{N}} \lambda_{n}(t) d t+(N-1) \tau_{p}+\tau_{r}\right\}
$$

where $\tau_{p}$ is the shutdown time for preventive maintenance, $\tau_{m}$ is the shutdown time for minor fault maintenance, and $\tau_{r}$ is the shutdown time for replacement maintenance. The total maintenance cost is:

$$
\begin{aligned}
& C_{\text {total }}=C_{d}+C_{r}+N C_{f}+\frac{N(N+1)}{2} C_{v}+ \\
& C_{m r} \times\left(\int_{0}^{T_{1}} \sum_{j=1}^{k} \lambda_{1 j}(t) d t+\mathrm{L}+\int_{0}^{T_{n}} \sum_{j=1}^{k} \lambda_{n j}(t) d t\right)
\end{aligned}
$$

Therefore, the optimal preventive maintenance times and the optimal incomplete preventive maintenance interval are obtained by optimizing the total maintenance $\operatorname{cost} C_{L}$ per unit time of system $L$.

$$
\begin{gathered}
C_{L}=\frac{C_{d}+C_{r}+N C_{f}+\frac{N(N+1)}{2} C_{v}}{\sum_{i=1}^{N} T_{i}}+ \\
\frac{C_{m r} \times\left(\int_{0}^{T_{1}} \sum_{j=1}^{k} \lambda_{1 j}(t) d t+\int_{0}^{T_{2}} \sum_{j=1}^{k} \lambda_{N j}(t) d t\right)}{\sum_{i=1}^{N} T_{i}}
\end{gathered}
$$

The cumulative failure risk of system $L$ in the first maintenance interval is not fully preventive maintenance when the reliability threshold $R_{0}$ is reached. The reliability equation is as follows:

$$
\begin{aligned}
& \exp \left[-\int_{0}^{T_{1}} \sum_{j=1}^{k} \lambda_{1 j}(t) d t\right]=\mathrm{L}= \\
& \exp \left[-\int_{0}^{T_{N}} \sum_{j=1}^{k} \lambda_{N j}(t) d t\right]=R_{0}
\end{aligned}
$$

After transformation:

$$
\begin{aligned}
& \int_{0}^{T_{1}} \sum_{j=1}^{k} \lambda_{1 j}(t) d t=\int_{0}^{T_{2}} \sum_{j=1}^{k} \lambda_{2 j}(t) d t=\mathrm{L}= \\
& \int_{0}^{T_{N}} \sum_{j=1}^{k} \lambda_{N j}(t) d t=-\ln R_{0}
\end{aligned}
$$

To improve the task of a metro train, it is necessary to have a high availability of metro trains. Availability is defined as the ratio of the total running time of metro trains to the running time (including failure and maintenance time) [19]:

$$
U_{A}=\frac{T_{\text {work }}}{T_{\text {work }}+T_{\text {notwork }}}
$$

where $T_{\text {work }}$ is the average working time and $T_{\text {notwork }}$ is the average nonworking time. Therefore, the availability of the system during a replacement maintenance cycle is as follows:

$$
\begin{aligned}
& U_{A}= \\
& \sum_{i=1}^{N} T_{i} \\
& \sum_{i=1}^{N} T_{i}+\tau_{m} \sum_{n=1}^{N} \int_{0}^{T_{N}} \lambda_{n}(t) d t+(N-1) \tau_{p}+\tau_{r}
\end{aligned}
$$

Finally, based on the incomplete preventive maintenance model of the competitive Weibull theory: 


$$
\left\{\begin{array}{l}
\frac{\min C_{L}=}{C_{d}+C_{r}+N C_{f}+\frac{N(N+1)}{2} C_{v}} \\
\frac{\sum_{i=1}^{N} T_{i}}{C_{m r} \times \sum_{i=1}^{N}\left(\int_{0}^{T_{N}} \sum_{j=1}^{k} \lambda_{i j}(t) d t\right)} \\
\sum_{i=1}^{N} T_{i} \\
\text { s.t. } \int_{0}^{T_{N}} \sum_{j=1}^{k} \lambda_{N j}(t) d t=-\ln R_{0} \\
R_{0}>0 ; k>0 ; j=1,2 \mathrm{~L} k ; N>0 ; \\
i=1,2, \mathrm{~L} N ;
\end{array}\right\}
$$

\section{Pretreatment of fault data}

To evaluate reliability with the competitive Weibull model, the problem of separating fault data $\left\{t_{1}, t_{2}, \mathrm{~L} t_{n}\right\}$ from $k$ fault mechanism data $\left\{t_{1}{ }^{i}, t_{2}{ }^{i}, \mathrm{~L} t_{n}{ }^{i}\right\}$ must be solved. Fault data can essentially be separated by analyzing the fault mechanism. However, due to the lack of information and huge workload, fault mechanism analysis is impossible to complete. Another solution is adopted in this article. First, a new concept, the characteristic attributes of faults, is established. The concept of fault feature attributes in this paper is as follows: in the process of metro vehicle operation, fault feature attributes are the set of random events or minimum random events that cause system $\mathrm{L}$ to fail. Second, through analysis of fault data, the fuzzy relationship between a fault and fault stress is established, the similarity of the fault mechanism is represented by the fault stress similarity, and the fault information sequence representing the characteristic attributes of faults is obtained. Finally, the fault information sequence is analyzed by fuzzy clustering. Because the values in the fault information sequences represent the eigenvalues of the corresponding fault mechanisms, the similarity of the eigenvalues is the similarity of the fault mechanisms. Thus, the fault data can be classified, analysis of fault mechanism can be avoided and the requirement of the competitive Weibull model can be satisfied.

The flow chart of the solution is as follows:

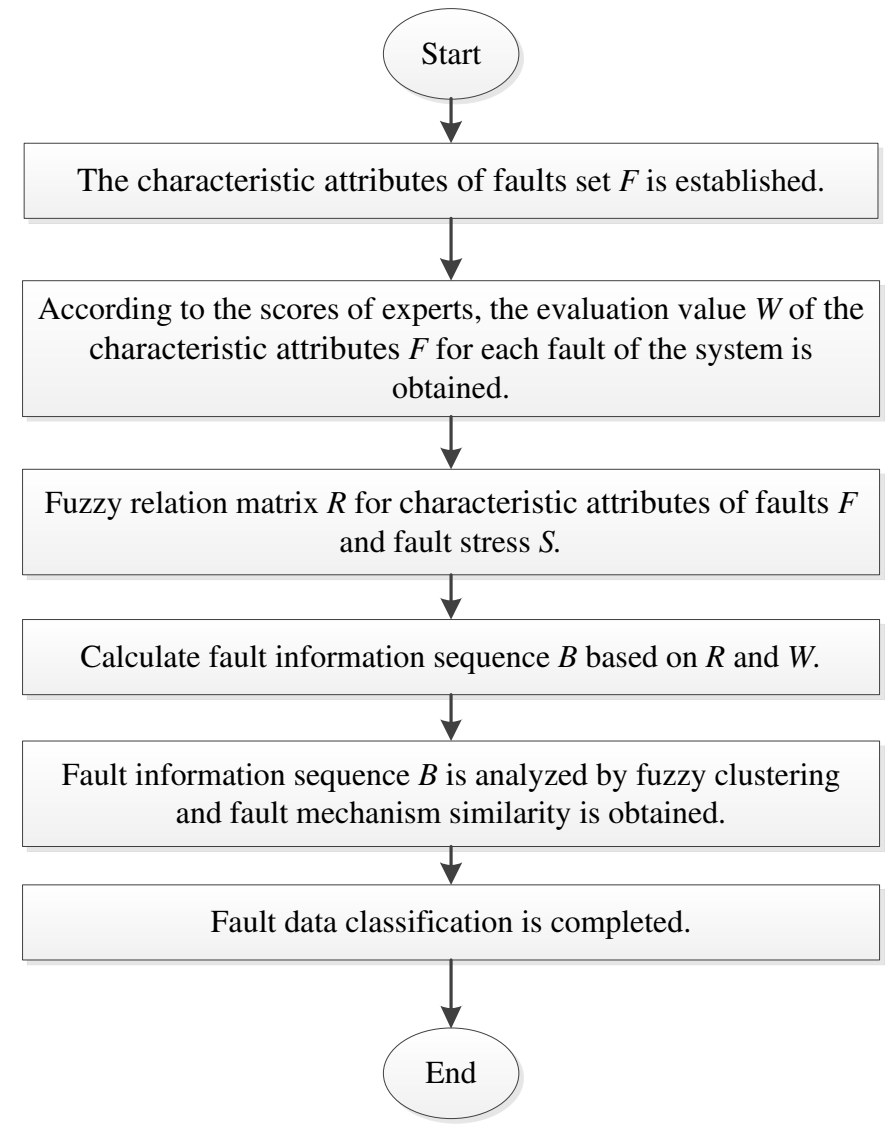

Fig. 1. Flow chart for data preprocessing

\subsection{Relationship between fault and fault stress}

Usually, a fault is represented by three factors: the fault mode, fault mechanism and fault stress [36]. A fault mechanism is a dynamic or static process in which fault stress acts until failure modes occur. Because of the complexity of mechanical systems, there are many combinations among these three elements [37]. There are many failure mechanisms in a metro vehicle system. Even if a simple part is broken, the cause and process of its formation are not singular but are a complex process of fault transmission, which makes it difficult to clearly describe the fault mechanism in a simple way or with a simple formula. The most important factor that affects the fault mechanism is the fault stress. The same process of fault stress action is similar, but the different process of stress action is certainly different. To avoid analysis of the fault mechanism, the similarity of fault stress is used to represent the similarity of the fault mechanism in this paper. The relationship between a fault and fault stress is established by the mathematical method of fuzzy evaluation, and the fuzzy evaluation results are used as the sequence of fault information to characterize the characteristics of the fault mechanism corresponding to each fault.

In this paper, the characteristic attributes of faults are defined as the random events or the minimum set of random events that cause system $L$ to fail during the operation of metro vehicles. Therefore, random fault events are equivalent to the bottom events in fault tree analysis, and the characteristic attributes of 
faults are equivalent to the smallest cut set of the fault tree. The fault is represented by $F$, and the minimum cut set $\left(f_{1}, f_{2}, \mathrm{~L} f_{n}\right)$ that causes the fault $F$ to occur can be obtained. The minimum cut set constitutes the characteristic attributes of fault $F$, and the characteristic attributes of fault $F$ are represented by $F=\left(f_{1}, f_{2}, \mathrm{~L} f_{n}\right)$. The next step is fuzzy evaluation of the fault stress set $S=\left\{s_{1}, s_{2}, \mathrm{~L} s_{m}\right\}$ and the characteristic attributes of the faults set $F=\left(f_{1}, f_{2}, \mathrm{~L} f_{n}\right)$.

The specific methods of fuzzy evaluation are as follows: By combining the actual working conditions and the external environment of the system, the fault stress selection set $S=\left\{s_{1}, s_{2}, s_{3}, s_{4}, s_{5}\right\}$, where $S=\{$ working stress, internal stress, working environment stress, accidental factor stress, artificial factor stress $\}$, is determined. The fuzzy relation matrix between fault stress and the fault cannot obtain an accurate value. For this reason, according to expert knowledge, the fuzzy relation matrix $R$ can be calculated by using the binary comparison ranking method. The bivariate comparative ranking method is a commonly used method to determine the membership function, the simplest of which is the preferential ranking method. Assuming that one of the characteristic attributes of the fault is stimulated by $m$ fault stresses, enough experienced professionals are required to compare the $m$ fault stresses in two ways to determine which fault stress is most likely to cause the occurrence of the fault characteristic attribute, and one of the most probable occurrences of the two is recorded once. Thus, the occurrence times of $m$ fault stresses are obtained. According to the number of occurrences of each fault stress, the total number of occurrences of the corresponding fault stress is removed based on the total number of occurrences in the first place:

$$
r_{i j}=\frac{t_{j}}{\max \left(t_{j}\right)} \quad j=1,2,3 \mathrm{~L} m
$$

The fuzzy relation matrix between the characteristic attributes of faults and fault stress is obtained:

$$
R=\left[\begin{array}{llll}
r_{11} & r_{12} & \mathrm{~L} & r_{1 m} \\
r_{21} & r_{22} & \mathrm{~L} & r_{2 m} \\
\mathrm{M} & \mathrm{M} & & \mathrm{M} \\
r_{n 1} & r_{n 2} & \mathrm{~L} & r_{n m}
\end{array}\right]
$$

where $r_{i j}$ is the fuzzy relationship between $f_{i}$ (the characteristic attributes) of fault $F$ and fault stress $S_{j}$.

\subsection{Weight of the characteristic attributes of faults and the fault information sequence}

The weight of the characteristic attributes of a fault is not only the expression of importance but also the degree of correlation with the fault. In this paper, the fuzzy complementary matrix $A$ of the characteristic attributes of faults is established by fuzzy evaluation:

$$
R=\left[\begin{array}{llll}
r_{11} & r_{12} & \mathrm{~L} & r_{1 m} \\
r_{21} & r_{22} & \mathrm{~L} & r_{2 m} \\
\mathrm{M} & \mathrm{M} & & \mathrm{M} \\
r_{n 1} & r_{n 2} & \mathrm{~L} & r_{n m}
\end{array}\right]
$$

where $a_{i j}$ is the importance of $i$ (the characteristic attributes of fault) and $j$ (the characteristic attributes of fault) to the fault mode.

Table 1 Fuzzy evaluation scale.

\begin{tabular}{ccc}
\hline $\begin{array}{c}\text { Serial } \\
\text { number }\end{array}$ & The Importance of $\boldsymbol{a}_{i}$ and $\boldsymbol{a}_{j}$ & Scale $\boldsymbol{a}_{\boldsymbol{i}}$ \\
\hline 1 & $a_{i}$ is as important as $a_{j}$ & 0.5 \\
2 & $a_{i}$ is slightly more important than $a_{j}$ & 0.6 \\
3 & $a_{i}$ is much more important than $a_{j}$ & 0.7 \\
4 & $a_{i}$ is very much more important than $a_{j}$ & 0.8 \\
5 & $a_{i}$ is absolutely more important than $a_{j}$ & 0.9 \\
6 & demagnetizing factor & $0.1,0.2,0.3,0.4$ \\
\hline
\end{tabular}

The fuzzy complementary matrix $A$ is modified so that the fuzzy consistent matrix can be satisfied. The requirements are as follows:

$$
\begin{aligned}
& \text { (1) } a_{i i}=0.5, i=1,2, \mathrm{~L} n \\
& \text { (2) } a_{i j}=1-a_{j i}, i, j=1,2, \mathrm{~L} n ; \\
& \text { (3) } a_{i j}=a_{i k}-a_{k j}, i, j, k=1,2, \mathrm{~L} n \text {; }
\end{aligned}
$$

The weight $A$ of the characteristic attributes of a fault can be obtained by the following formulas:

$$
\begin{gathered}
W_{p}=\left(w_{p 1}, w_{p 2}, \mathrm{~L} w_{p n}\right) \\
w_{p i}=\beta^{\frac{1}{n} \sum_{j=1}^{n} a_{i j}} / \sum_{k=1}^{n} \beta^{\frac{1}{n} \sum_{j=1}^{n} a_{k j}}
\end{gathered}
$$

where $\beta$ is the resolution parameter of weight allocation. Similarly, the weight $W=\left(W_{1}, W_{2}, \mathrm{~L}, W_{p}\right)$ of the system failure mode $F_{1}, F_{2}, \mathrm{~L} F_{p}$ can be obtained.

Therefore, the fuzzy evaluation value of fault stress $B$ (fault information sequence) can be obtained:

$$
B_{p}=W_{p} \times R_{p}
$$

Similarly, the fault information sequence of system failure mode B can be obtained: $B=\left(B_{1}, B_{2}, \mathrm{~L}, B_{p}\right)$.

\subsection{Fuzzy clustering analysis of fault data}

After the fault information sequence of the fault data is obtained, the fault information sequence is used to represent the fault, the numerical value in the fault information sequence is used to represent the eigenvalues of the fault mechanism, and the similarity of the eigenvalues is used to represent the similarity of the fault mechanism. The similarity of the fault mechanism can then be obtained by analyzing the similarity of the fault sequence with the method of fuzzy clustering. According to the similarity of the fault information sequence, a fuzzy similarity matrix $C=\left(c_{i j}\right)_{n \times n}$ is established, where $c_{i j}$ 
represents the similarity between fault $B_{i}$ and fault $B_{j}$, where $c_{i j}$ is:

$$
c_{i j}=\frac{\sum_{k=1}^{m}\left|c_{i k}-\bar{c}_{i}\right| \bullet\left|c_{j k}-\bar{c}_{j}\right|}{\sqrt{\sum_{k=1}^{m}\left(c_{i k}-\bar{c}_{i}\right)^{2}} \bullet \sqrt{\sum_{k=1}^{m}\left(c_{j k}-\bar{c}_{j}\right)^{2}}}
$$

where: $\bar{c}_{i}=\frac{1}{m} \sum_{k=1}^{m} c_{i k}, \bar{c}_{j}=\frac{1}{m} \sum_{k=1}^{m} c_{j k}$.

Generally, the fuzzy relation $C$ established by the above method only has reflexivity and symmetry and does not satisfy transitivity. Therefore, it is necessary to solve the transitive closure $t(C)$ of the fuzzy matrix. Starting from the transfer matrix $C, \quad C \rightarrow C^{2} \rightarrow C^{4} \rightarrow \mathrm{L} \rightarrow C^{k}$ are calculated by using the square method until the first discovery of $C^{k}=C^{2 k}$, where $C^{k}$ is the transitive closure $t(C)$ of $C$. The calculation method is as follows:

$$
\begin{gathered}
C^{2}=\left(C_{i j}^{(2)}\right)_{(n \times n)}=C \bullet C \\
C^{3}=C^{2} \bullet C \\
C^{4}=C^{3} \bullet C \\
\mathrm{~N}
\end{gathered}
$$

in the above formulas: $C_{i j}^{(2)}=\underset{k=1}{\vee}\left(c_{i k} \wedge b_{k j}\right)$.

$\bar{C}=t(C)$ is the fuzzy equivalence matrix of $C$, and if $\lambda$ is the threshold of fuzzy clustering, the equivalence matrix is:

$$
\begin{gathered}
C_{\lambda}=\left(c_{i j}^{(\lambda)}\right)_{n \times n} \\
c_{i j}{ }^{(\lambda)}= \begin{cases}1, & \bar{c}_{i j} \geq \lambda \\
0, & \bar{c}_{i j}<\lambda\end{cases}
\end{gathered}
$$

According to $C, B$ (the fault information sequence) whose element value is 1 in each column is classified as a group, thus realizing classification of the fault mechanism by the fault data, i.e., clustering analysis of the fault time $\left\{t_{1}, t_{2}, \mathrm{~L} t_{n}\right\}$.

\section{Solution of the model}

\subsection{Parameter estimation in the competitive Weibull model}

Metro vehicles have high reliability. Thus, there are fewer effective fault data and they need to be classified, so it is difficult to satisfy the requirement of a statistical sample size, that is, the competitive Weibull model evaluation must use a small sample. Therefore, the parameters in the competitive Weibull model are estimated by the method of graph parameter estimation.

(1) Linearization of the Weibull model. First, assuming that every fault distribution of system $L$ obeys a two-parameter Weibull distribution, the analytic form of the fault rate function is as follows:

$$
\begin{aligned}
& \lambda_{L}=\lambda_{1}+\lambda_{2}+\mathrm{L}+\lambda_{k}= \\
& \frac{\beta_{1}}{\eta_{1}^{\beta_{1}}} t^{\beta_{1}-1}+\frac{\beta_{2}}{\eta_{2}^{\beta_{2}}} t^{\beta_{2}-1}+\mathrm{L}+\frac{\beta_{k}}{\eta_{k}^{\beta_{k}}} t^{\beta_{k}-1} \\
& (j=1,2,3 \mathrm{~L} k) \\
& R(t)=\exp \left[-\left(\frac{t}{\eta}\right)^{\beta}\right]
\end{aligned}
$$

The linear regression model of the Weibull distribution can be obtained by two logarithms:

$$
y_{i}=\hat{a}+\hat{b} x_{i}, i=1,2,3 \mathrm{~L} n
$$

In the above formulas: $y_{i}=\ln \left\{-\ln R\left(t_{i}\right)\right\}, x_{i}=\ln t_{i}$, $a=-\beta \ln \eta$, and $-b=\beta$.

(2) Because of the small sample size, the median rank method is used to calculate the reliability of the set. The reliability of $\mathrm{R}$ is estimated as follows:

$$
R\left(t_{i}\right)=\frac{[(n+1)-i-0.3]}{(n+0.4)}
$$

(3) From formulas (30), (31), (32) and $Y$, the Weibull probability maps of the fault time interval are drawn on the Weibull probability paper in turn.

(4) Two asymptotic lines are fitted on the Weibull probability map. The expression of an asymptote is $y=k x+b$, which is the asymptote of $x \rightarrow+\infty$. The other asymptote is perpendicular to the $x$ axis and is located on the left side of all the scattering points. The expression is $x=x_{0}$. Thus, the following equation can be obtained:

$$
\left\{\begin{array}{l}
\beta \ln (\eta)=a \\
-\beta=b
\end{array}\right.
$$

The estimation of the two parameters of the Weibull distribution based on the graph parameter estimation method is completed.

\subsection{Solution of the competitive Weibull Preventive Maintenance Model Based on Quantum-Genetic Algorithms}

The competitive Weibull model is substituted into the objective function. Through the objective function and constraints, the reliability threshold $R_{p}$ for ensuring the safe operation of trains and the optimal preventive maintenance number $N$ in a cycle are taken as decision variables, and then, the preventive maintenance interval $T_{N}$ for ensuring the safety and economy of trains can be obtained. In this paper, the quantum-genetic algorithm is used to optimize the process of solving the objective function.

The genetic algorithm (GA) [38] comes from the observation of biological evolution and genetic phenomena in nature. The GA is a global optimization algorithm with parallel computing 
ability. The advantage of the GA is that it has high search efficiency, good versatility, parallelism and robustness. However, the GA also has some limitations, such as poor local search ability, slow search speed, and can easily reach "premature" solutions. To overcome these limitations, the quantum-genetic algorithm has a larger population size and a stronger global search ability. Population evolutionary learning in the traditional GA is adopted in the QGA [39]. For individuals in the population, when the population evolves to the $t$-th generation, the expression of the population is shown in Formula (34):

$$
Q(t)=\left\{q_{1}, q_{2}, \mathrm{~L}, q_{n}\right\}
$$

where $n$ is the population length and $q_{i}^{t}(i=1,2, \mathrm{~K}, n)$ is the chromosome. For the QGA, the common quantum gates have multiple operators, which can be selected according to the characteristics of practical problems in the process of solving problems. Because of its convenience of operation and high efficiency for individual evolution, quantum revolving door is the most commonly used quantum operation algorithm. The adjustment operation of quantum revolving door is as follows:

$$
U\left(\theta_{i}\right)=\left[\begin{array}{cc}
\cos \left(\theta_{i}\right) & -\sin \left(\theta_{i}\right) \\
\sin \left(\theta_{i}\right) & \cos \left(\theta_{i}\right)
\end{array}\right]
$$

The updating process is as follows:

$$
\begin{aligned}
& {\left[\begin{array}{l}
\alpha_{i}^{\prime} \\
\beta_{i}^{\prime}
\end{array}\right]=U\left(\theta_{i}\right)\left[\begin{array}{l}
\alpha_{i} \\
\beta_{i}
\end{array}\right]=} \\
& {\left[\begin{array}{lr}
\cos \left(\theta_{i}\right) & -\sin \left(\theta_{i}\right) \\
\sin \left(\theta_{i}\right) & \cos \left(\theta_{i}\right)
\end{array}\right]\left[\begin{array}{l}
\alpha_{i} \\
\beta_{i}
\end{array}\right]}
\end{aligned}
$$

In the above formulas, $\left(\alpha_{i}, \beta_{i}\right)^{T}$ and $\left(\alpha_{i}^{\prime}, \beta_{i}^{\prime}\right)^{T}$ represent the probabilistic amplitude of the chromosome $i$-th qubit revolving gate before and after renewal. $\theta_{i}$ is the revolving angle, and its size and symbol are determined by the predesigned adjustment strategy.

$$
\begin{gathered}
\left\{\begin{array}{l}
\alpha_{i}^{\prime}=\alpha_{i} \cos \left(\theta_{i}\right)-\beta_{i} \sin \left(\theta_{i}\right) \\
\beta_{i}^{\prime}=\alpha_{i} \sin \left(\theta_{i}\right)+\beta_{i} \cos \left(\theta_{i}\right)
\end{array}\right. \\
\left|\alpha_{i}^{\prime}\right|^{2}+\left|\beta_{i}^{\prime}\right|^{2}=\left[\alpha_{i} \cos \left(\theta_{i}\right)-\beta_{i} \sin \left(\theta_{i}\right)\right]^{2}+ \\
{\left[\alpha_{i} \sin \left(\theta_{i}\right)+\beta_{i} \cos \left(\theta_{i}\right)\right]^{2}} \\
=\left|\alpha_{i}\right|^{2}+\left|\beta_{i}\right|^{2}=1
\end{gathered}
$$

It can be seen that the value of $\left|\alpha_{i}^{\prime}\right|^{2}+\left|\beta_{i}^{\prime}\right|^{2}$ after transformation is still 1 .

The flow of the QGA is similar to that of the basic genetic algorithm. On the basis of determining the fitness function, the strategy of randomly initializing the quantum population and promoting population evolution is adopted, and then, the optimal solution in the solution space is obtained. The implementation steps of the quantum genetic algorithm are as follows:

(1) Initialize the algorithm parameters, including the individual binary coding length $L$, population size $N$ and maximum number of iterations $T$.

(2) Population $Q\left(t_{0}\right)$ is initialized by the random initialization method; then, set $G\left(t_{0}\right)$ is coded by the binary system, and the individual state value is obtained by a collapse operation.

(3) The applicability of the individual is calculated according to the individual state value, and the correctness of the cross experiment is used as the formula to evaluate the fitness : Fitness $=\frac{\text { Socr }}{s} \times 100 \%$.

(4) Individuals are updated by the method of revolving door.

(5) To determine whether the algorithm terminates, the optimal individual and its corresponding fitness are recorded, the optimal result of the algorithm is recorded, and the termination algorithm is terminated. Otherwise enter (6).

(6) The quantum rotary gate update is set.

(7) The new population $\mathrm{Q}$ is obtained for iteration times+1, return to (3).

The flow chart for the algorithm is as follows:

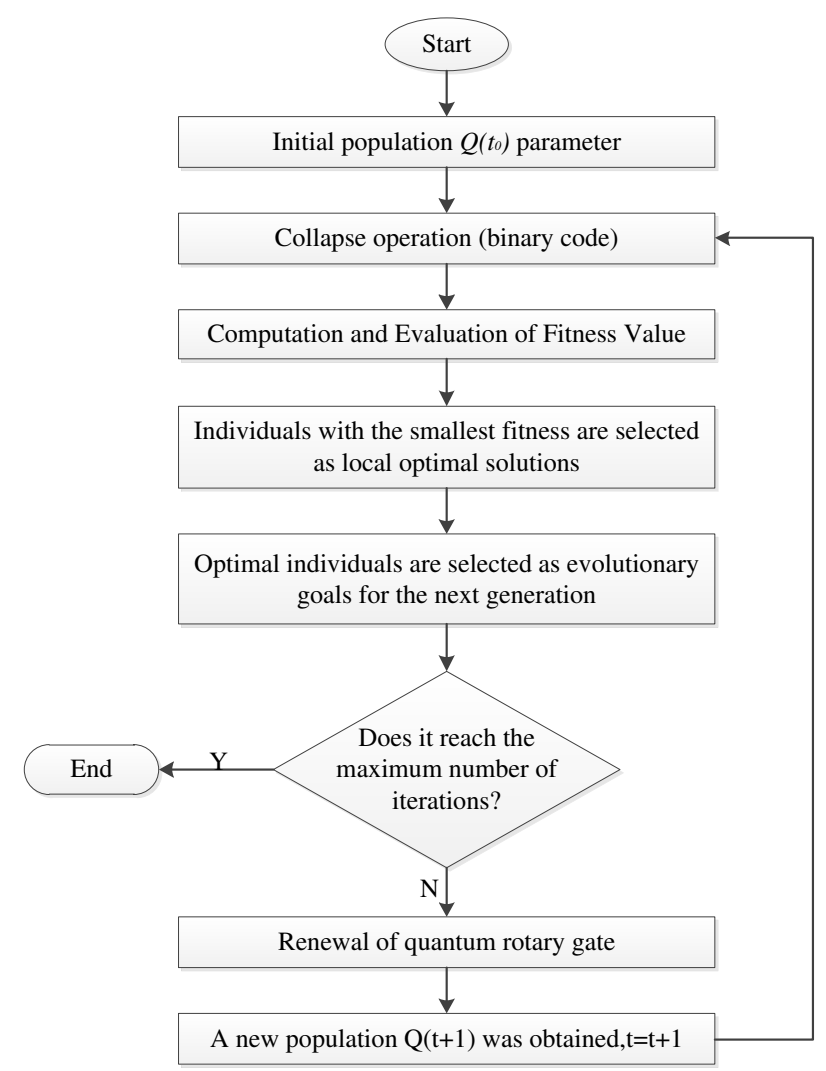

Fig. 2. Flow chart for the quantum-genetic algorithm

The specific operation method in Fig. 2 is as follows:

(1) Population Initialization: according to the size and difficulty of solving the problem, the algorithm 
parameters, including the population size and individual length, are initialized.

(2) Collapse Operation: measure the individual gene quantum and record the current state as $Q(t)$.

(3) Fitness Calculation: fitness is calculated according to $Q(t)$ and the fitness function.

(4) Revolving Door Update: revolving door is used to update individuals.

\section{Example verification}

To prove show the rationality and superiority of the maintenance optimization strategy proposed in this paper, the maintenance strategy of the train door system in Nanning Metro is taken as an example.

Table 2 Fault pattern set, characteristic attributes of faults and fault impact grade of the door system.

\subsection{Characteristic attributes and information sequence of faults analysis}

First, according to the maintenance records of the train door system, the characteristic attributes of faults and the fault impact grade of the fault mode set are obtained, as shown in Table 2.

Eight types of fault modes are then selected for reliability analysis, and the fault sets are selected as follows: $F=\left\{F_{1}\right.$ abnormal sound of the metro door, $F_{2}$ air leakage through the metro door, $F_{3}$ the door pops open after closing, $F_{4}$ jitter of the metro door, $F_{5}$ buzzer failure, $F_{6}$ deformation of the door shield, $F_{7}$ door friction noise is too loud, $F_{8}$ interference between the door pages and balanced press wheel $\}$. Next, the weights of the characteristic attributes of the faults of the 8 types of selected fault modes are obtained.

\begin{tabular}{|c|c|c|}
\hline Fault pattern set & Characteristic attributes of faults & Fault impact grade \\
\hline Abnormal sound of the metro door & $\begin{array}{c}\text { Loose fastening bolt for the lock tongue in the square hole of the door side roof } \\
\text { Side door antispring wheel loosening } \\
\text { Square hole lock antiloosening line dislocation }\end{array}$ & Slight \\
\hline Air leakage through the metro door & $\begin{array}{c}\text { Abnormal size of door alignment } \\
\text { V-shape size abnormality of the door } \\
\text { Abnormal gap of the finger protector tape } \\
\text { Abnormal parallelism }\end{array}$ & Slight \\
\hline The door pops open after closing & $\begin{array}{l}\text { Passengers lean against the door } \\
\text { Obstacles at the door } \\
\text { Door controller failure }\end{array}$ & Serious \\
\hline Jitter of the metro door & $\begin{array}{l}\text { Abnormal clearance between the lower pin side and block } \\
\text { Door opening beyond its normal range }\end{array}$ & Commonly \\
\hline Buzzer failure & Loose connection of the buzzer & Slightly Serious \\
\hline Deformation of the door shield & Passenger extrusion deformation & Serious \\
\hline Door friction noise is too loud & Abnormal clearance between the side of the lower gear pin and block & Slight \\
\hline
\end{tabular}

Intervention between the door pages and balanced press wheel
Passengers squeeze doors Abnormal position of the balanced press wheel Long-term vibration Collision of door pages
First, we consider that $F_{1}$ abnormal sound of the metro door $=\left\{f_{1}\right.$ loose fastening bolt for the lock tongue in the square hole of the door side roof, $f_{2}$ side door anti-spring wheel loosening, $f_{3}$ square hole lock antiloosening line dislocation\}. Thus, the fuzzy consistent matrix can be obtained as follows:

$$
A_{1}=\left[\begin{array}{lll}
0.5 & 0.6 & 0.7 \\
0.4 & 0.5 & 0.8 \\
0.3 & 0.2 & 0.5
\end{array}\right]
$$

The weight of the characteristic attributes of the faults can be obtained by formula (24):

$W_{1}=\left(\begin{array}{lll}0.198 & 0.226 & 0.577\end{array}\right)$. According to the above steps, it can be found that:

$$
\begin{aligned}
& W_{2}=\left(\begin{array}{llll}
0.161 & 0.244 & 0.244 & 0.363
\end{array}\right) \\
& W_{3}=\left(\begin{array}{lll}
0.212 & 0.316 & 0.472
\end{array}\right) \quad W_{4}=\left(\begin{array}{lll}
0.601 & 0.399
\end{array}\right) \\
& W_{5}=(1) W_{6}=\left(\begin{array}{llll}
0.182 & 0.122 & 0.246 & 0.449
\end{array}\right) \\
& W_{7}=(1) \quad W_{8}=(1) \text {. }
\end{aligned}
$$

The Metro plug door system is a complex mechanical system of mechatronics, which includes many subsystems. The system has a long working time and high working frequency. Therefore, the system bears a variety of complex fault stresses, which can be divided into three categories:

(1) Stress of the plug door to complete its basic operational function

(2) The environmental stress of the plug door when it is working. Environmental stress can also be divided into two kinds: the stress acting on the plug door by the 
external environment while it works; the stress produced by the internal parts of the plug door when it works.

(3) Failure of the plug door is caused by man-made factors, that is, man-made stress.

Take the failure mode " $F_{1}$ abnormal sound of the metro door $"$ as an example. Aiming at the characteristic attributes of fault $\left(F_{1}\right) f_{1}=$ loose fastening bolt for the lock tongue in the square hole of the door side roof, according to the stress set $S=\left\{\quad S_{1}\right.$ working stress, $S_{2}$ internal stress, $S_{3}$ working environment stress, $S_{4}$ accidental factor stress, $S_{5}$ human factor stress $\}$ selection and sorting are carried out. When the excitation effects of $s_{1}$ and $s_{2}$ on $f_{1}$ are compared, if $s_{1}$ is more effective than $S_{2}$, remember that $S_{1}$ occurs once (if both have no obvious relationship with $f_{1}$, they do not occur).

Table 3 Binary contrast sorting table.

\begin{tabular}{ccccccc}
\hline$f_{1}$ & $S_{1}$ & $S_{2}$ & $S_{3}$ & $S_{4}$ & $S_{5}$ & Occurrences $t$ \\
\hline$s_{1}$ & 12 & 18 & 25 & 30 & 30 & 103 \\
$s_{2}$ & 5 & 9 & 21 & 30 & 30 & 93 \\
$s_{3}$ & 0 & 0 & 10 & 10 & 30 & 54 \\
$s_{4}$ & 0 & 0 & 0 & 15 & & 25 \\
$s_{5}$ & 0 & & & & 15 \\
\hline
\end{tabular}

According to formula (20), we can obtain:

$$
\begin{aligned}
& r_{11}=\frac{103}{103}=1, r_{12}=\frac{93}{103}=0.90, r_{13}=\frac{54}{103}=0.52, \\
& r_{14}=\frac{25}{103}=0.24, r_{15}=\frac{15}{103}=0.14
\end{aligned}
$$

This result corresponds to the first row element of $R_{l}$ in the fuzzy relation matrix. According to the above method, the fuzzy relation matrix $R_{l}$ is:

$$
R_{1}=\left[\begin{array}{lllll}
1 & 0.90 & 0.52 & 0.24 & 0.14 \\
1 & 0.84 & 0.86 & 0.87 & 0.38 \\
1 & 0.79 & 0.54 & 0.31 & 0.21
\end{array}\right]
$$

Thus, the fuzzy evaluation value $B_{I}$ (fault information sequence) of fault $F_{l}$ " abnormal sound of the metro door " to fault stress can be obtained:

$$
\begin{aligned}
& B_{1}=W_{1} \times R_{1}= \\
& {\left[\begin{array}{lllll}
1.001 & 0.824 & 0.609 & 0.423 & 0.235
\end{array}\right]}
\end{aligned}
$$

In the same way:

$$
\begin{aligned}
R_{2} & =\left[\begin{array}{ccccc}
0.88 & 1 & 0.62 & 0.78 & 0.64 \\
0.75 & 0.73 & 1 & 0.30 & 0.19 \\
1 & 0.90 & 0.96 & 0.59 & 0 \\
0.86 & 0.52 & 0.38 & 0.09 & 1
\end{array}\right] \\
R_{3} & =\left[\begin{array}{ccccc}
0 & 0 & 0 & 0 & 1 \\
0 & 0 & 0.14 & 0.86 & 1 \\
1 & 0.83 & 0.91 & 0.48 & 0.23
\end{array}\right] \\
R_{4} & =\left[\begin{array}{ccccc}
1 & 0.77 & 0.36 & 0.70 & 0.26 \\
0.91 & 1 & 0.32 & 0.14 & 0.36
\end{array}\right] \\
R_{5} & =\left[\begin{array}{ccccc}
1 & 0.66 & 0 & 0.25 & 0
\end{array}\right] \\
R_{6} & =\left[\begin{array}{ccccc}
0.63 & 0.72 & 1 & 0 & 0.43 \\
0 & 0 & 0 & 0 & 1 \\
1 & 0.89 & 0.69 & 0.27 & 0.19 \\
0.80 & 1 & 0.90 & 0 & 0
\end{array}\right] \\
R_{7} & =\left[\begin{array}{lllll}
0.636 & 1 & 0.745 & 0.200 & 0.145
\end{array}\right] \\
R_{8} & =\left[\begin{array}{lllll}
0 & 0 & 0 & 0.46 & 1
\end{array}\right]
\end{aligned}
$$

Thus, the fuzzy evaluation value (fault information sequence) of other faults to the fault stress can be obtained:

$$
\begin{aligned}
& B_{1}=W_{1} \times R_{1}=\left[\begin{array}{lllll}
1.001 & 0.824 & 0.609 & 0.423 & 0.235
\end{array}\right] \\
& B_{2}=W_{2} \times R_{2}=\left[\begin{array}{lllll}
0.870 & 0.738 & 0.706 & 0.371 & 0.508
\end{array}\right] \\
& B_{3}=W_{3} \times R_{3}=\left[\begin{array}{lllll}
0.472 & 0.392 & 0.474 & 0.498 & 0.637
\end{array}\right] \\
& B_{4}=W_{4} \times R_{4}=\left[\begin{array}{llllll}
0.964 & 0.862 & 0.344 & 0.477 & 0.300
\end{array}\right] \\
& B_{5}=W_{5} \times R_{5}=\left[\begin{array}{llllll}
1.000 & 0.658 & 0 & 0.250 & 0
\end{array}\right] \\
& B_{6}=W_{6} \times R_{6}=\left[\begin{array}{llllll}
0.719 & 0.798 & 0.756 & 0.066 & 0.247
\end{array}\right] \\
& B_{7}=W_{7} \times R_{7}=\left[\begin{array}{llllll}
0.636 & 1.000 & 0.745 & 0.200 & 0.145
\end{array}\right] \\
& B_{8}=W_{8} \times R_{8}=\left[\begin{array}{llllll}
0 & 0 & 0 & 0.460 & 1.000
\end{array}\right]
\end{aligned}
$$

The fault information sequence is used to represent the fault, and the clustering object is the set of the fault information sequence.

$B=\left\{B_{1}, B_{2}, B_{3}, B_{4}, B_{5}, B_{6}, B_{7}, B_{8}\right\}$. 


\subsection{Fuzzy Clustering Analysis of Fault Data}

The fuzzy similarity matrix $C$ of clustering object $B$ is calculated as follows:

$C=\left\{\begin{array}{llllllll}1.0000 & 0.4002 & 0.3631 & 0.3612 & 0.3846 & 0.4359 & 0.4436 & 0.4225 \\ 0.4002 & 1.0000 & 0.7817 & 0.7273 & 0.6748 & 0.6623 & 0.6632 & 0.6771 \\ 0.3631 & 0.7817 & 1.0000 & 0.6963 & 0.6371 & 0.6876 & 0.7541 & 0.6695 \\ 0.3612 & 0.7273 & 0.6963 & 1.0000 & 0.9289 & 0.6413 & 0.7130 & 0.7739 \\ 0.3846 & 0.6748 & 0.6371 & 0.9289 & 1.0000 & 0.5901 & 0.6548 & 0.7246 \\ 0.4359 & 0.6623 & 0.6876 & 0.6413 & 0.5901 & 1.0000 & 0.6220 & 0.7669 \\ 0.4436 & 0.6632 & 0.7541 & 0.7130 & 0.6548 & 0.6220 & 1.0000 & 0.6876 \\ 0.4225 & 0.6771 & 0.6695 & 0.7739 & 0.7246 & 0.7669 & 0.6876 & 1.0000\end{array}\right\}$

According to formulas (27) and (28), the transitive closure matrix is obtained:

$$
\bar{C}=\left\{\begin{array}{llllllll}
1.0000 & 0.8244 & 0.6551 & 0.8474 & 0.5940 & 0.7065 & 0.7065 & 0.4500 \\
0.8244 & 1.0000 & 0.6551 & 0.8244 & 0.5940 & 0.7065 & 0.7065 & 0.4500 \\
0.6551 & 0.6551 & 1.0000 & 0.6551 & 0.5940 & 0.6551 & 0.6551 & 0.4500 \\
0.8474 & 0.8244 & 0.6551 & 1.0000 & 0.5940 & 0.7065 & 0.7065 & 0.4500 \\
0.5940 & 0.5940 & 0.5940 & 0.5940 & 1.0000 & 0.5940 & 0.5940 & 0.4500 \\
0.7065 & 0.7065 & 0.6551 & 0.7065 & 0.5940 & 1.0000 & 0.8008 & 0.4500 \\
0.7065 & 0.7065 & 0.6551 & 0.7065 & 0.5940 & 0.8008 & 1.0000 & 0.4500 \\
0.4500 & 0.4500 & 0.4500 & 0.4500 & 0.4500 & 0.4500 & 0.4500 & 1.0000
\end{array}\right\}
$$

According to the fuzzy clustering method, the fuzzy clustering threshold $\lambda$ can be $1,0.8474,0.8244,0.8008$, $0.7250,0.6551,0.5940$, or 0.4500 , and the larger the value, the greater the number of clusters. At the time that $\lambda=1$, the number of clusters is 8 . When $\lambda=0.4500$, the number of clusters is 1 . The results of dynamic clustering are as follows:

$\lambda=0.5940$ and $\lambda=0.6551$ are calculated, and the equivalent relation matrix is obtained as follows:

From this, we can see that when $\lambda=0.6551$ and $\lambda=0.5940$, the fault data sets are divided into three categories: $\left\{t_{1}, t_{2}, t_{3}, t_{4}, t_{6}, t_{7}\right\},\left\{t_{5}\right\},\left\{t_{8}\right\}$ and $\left\{t_{1}, t_{2}, t_{3}, t_{4}, t_{5}, t_{6}, t_{7}\right\}$, $\left\{t_{8}\right\}$. The requirement of small sample data processing is considered, and the classification of $\lambda=0.5940$ is selected as the clustering result of the fault data set. Thus, data preprocessing of incomplete preventive maintenance of the metro train door system based on the competitive Weibull model is completed.

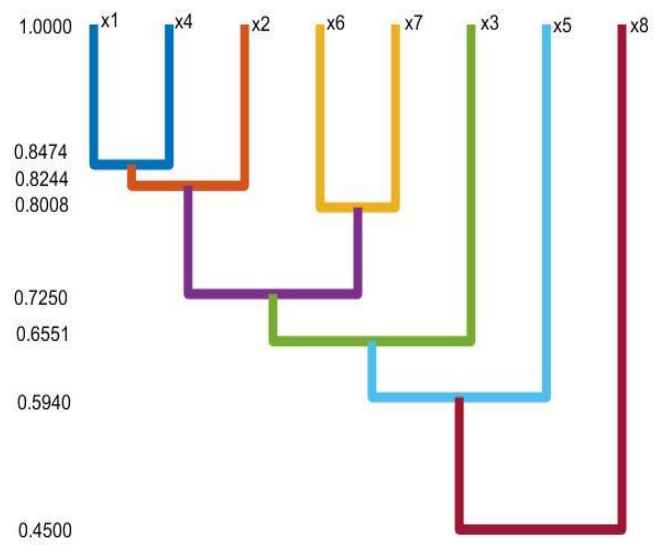

$$
\begin{aligned}
\bar{C}_{0.6551}= & \left\{\begin{array}{llllllll}
1 & 1 & 1 & 1 & 0 & 1 & 1 & 0 \\
1 & 1 & 1 & 1 & 0 & 1 & 1 & 0 \\
1 & 1 & 1 & 1 & 0 & 1 & 1 & 0 \\
1 & 1 & 1 & 1 & 0 & 1 & 1 & 0 \\
0 & 0 & 0 & 0 & 1 & 0 & 0 & 0 \\
1 & 1 & 1 & 1 & 0 & 1 & 1 & 0 \\
1 & 1 & 1 & 1 & 0 & 1 & 1 & 0 \\
0 & 0 & 0 & 0 & 0 & 0 & 0 & 1
\end{array}\right\} \\
\bar{C}_{0.5940}= & \left\{\begin{array}{lllllllll}
1 & 1 & 1 & 1 & 1 & 1 & 1 & 0 \\
1 & 1 & 1 & 1 & 1 & 1 & 1 & 0 \\
1 & 1 & 1 & 1 & 1 & 1 & 1 & 0 \\
1 & 1 & 1 & 1 & 1 & 1 & 1 & 0 \\
1 & 1 & 1 & 1 & 1 & 1 & 1 & 0 \\
0 & 0 & 0 & 0 & 0 & 0 & 0 & 1 \\
0 & 0 & 0 & 0 & 0 & 0 & 0 & 1 \\
0 & 0 & 0 & 0 & 0 & 0 & 0 & 1
\end{array}\right\}
\end{aligned}
$$

\subsection{Parameter analysis of the incomplete maintenance model based on the competitive Weibull theory}

According to the method presented in Chapter III- $A$, the parameters of the competitive Weibull model can be obtained as follows:

$$
\left\{\begin{array} { l } 
{ \eta _ { 1 } = 2 2 1 . 7 7 } \\
{ \beta _ { 1 } = 1 . 8 9 5 6 }
\end{array} \quad \left\{\begin{array}{l}
\eta_{2}=178.577 \\
\beta_{2}=1.9387
\end{array}\right.\right.
$$

As a result, the failure rate of the competitive Weibull model can be obtained as follows:

$$
\begin{aligned}
& \lambda(t)=\lambda_{1}(t)+\lambda_{2}(t)=\frac{\beta_{1}}{\eta_{1}^{\beta_{1}}} t^{\beta_{1}-1}+\frac{\beta_{2}}{\eta_{2}^{\beta_{2}}} t^{\beta_{2}-1} \\
& =\frac{1.8956}{221.77^{1.8956}} t^{0.8956}+\frac{1.9387}{178.577^{1.9387}} t^{0.9387}
\end{aligned}
$$

The reliability function of the competitive Weibull model is:

$$
R(t)=e^{\left[-\left(\frac{t}{221.77}\right)^{1.8956}-\left(\frac{t}{178.577}\right)^{1.9387}\right]}
$$

Similarly, the parameters and reliability of a single Weibull are calculated as:

$$
\begin{gathered}
\left\{\begin{array}{l}
\eta_{\mathrm{d}}=208.812 \\
\beta_{\mathrm{d}}=1.9085
\end{array}\right. \\
R(t)=e^{-\left(\frac{t}{208.812}\right)^{1.9085}}
\end{gathered}
$$

Then, the reliability image function of the door system of the single Weibull model and the competitive Weibull model without considering maintenance is as follows:

Fig. 3. Cluster analysis diagram 


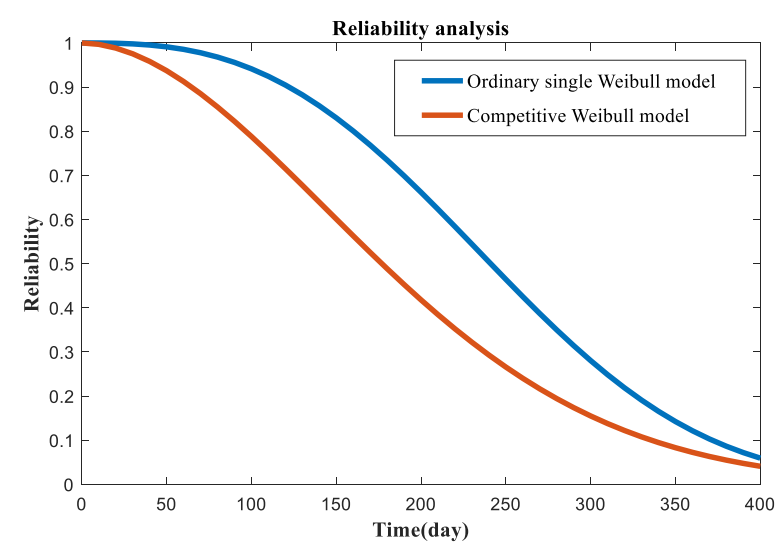

Fig. 4. Reliability Function of the Door System

A comparison between the competitive Weibull distribution and the ordinary single Weibull distribution is shown in Figure 4. In the figure, the reliability function curve of the competitive Weibull model is represented by the red line and the reliability function curve of the ordinary single Weibull model is represented by the blue line. It can be seen that the reliability of the competitive Weibull model is significantly lower than that of the ordinary Weibull model due to the complexity of the fault and the diversification of the fault mechanism. The objective existence of competitive failure and the phenomenon that "user reliability is significantly lower than the evaluation result" are considered, which is deemed to be reasonable in this paper.

The parameters of the system are set as shown in Table 4 below. The service age reduction factor $a_{n}$ and the fault rate increase factor $b_{n}$ are shown in formula (47):

$$
a_{n}=\frac{n}{3 n+7}, b_{n}=\frac{12 n+1}{11 n+1}
$$

Table 4

Parameter settings table.

\begin{tabular}{cc|cc}
\hline Parameter & $\begin{array}{c}\text { Numerical } \\
\text { value }\end{array}$ & Parameter & $\begin{array}{c}\text { Numerical } \\
\text { value }\end{array}$ \\
\hline$\beta_{1}$ & 1.8956 & $C_{f}$ /yuan & 652 \\
$\eta_{1}$ & 221.77 & $C_{v} /$ yuan & 55 \\
$\beta_{2}$ & 1.9385 & $C_{d} /$ yuan & 15000 \\
$\eta_{2}$ & 178.577 & $\tau_{p} /$ day & 0.8 \\
$C_{m r} /$ yuan & 2010 & $\tau_{r} /$ day & 3 \\
$C_{r} /$ yuan & 3050 & $\tau_{m} /$ day & 1.2 \\
\hline
\end{tabular}

\subsection{Calculation of the maintenance threshold, maintenance interval and maintenance time}

To highlight the superiority of the incomplete maintenance strategy based on the competitive Weibull model, we compare the more mature improvement maintenance strategy in the current research field with the maintenance strategy proposed in this paper. Using the same parameter setting and intelligent algorithm, the availability and maintenance cost are quantitatively analyzed.

In the field of metro train maintenance, we adopt a relatively mature maintenance strategy: On the basis of reliability analysis, we adopt a maintenance strategy that combines preventive complete maintenance [40] and preventive replacement (referred to as "complete maintenance strategy"). The objective function of the maintenance strategy model is:

$$
C_{\text {total } 2}=C_{m 2}+C_{p 2}+C_{r 2}+C_{d 2}
$$

where $C_{\text {total }}$ is the total cost of one maintenance cycle for the complete maintenance strategy, $C_{m 2}$ is the cost of minor repair, $C_{p 2}$ is the cost of preventive maintenance, $C_{r 2}$ is the cost of preventive replacement, and $C_{d 2}$ is the cost of parking loss. Specifically:

$$
\begin{aligned}
& C_{m 2}=\sum_{i=1}^{N} C_{m r} \times n_{i}= \\
& C_{m r} \times\left(\int_{0}^{T_{1}} \sum_{j=1}^{k} \lambda_{1 j}(t) d t+\mathrm{L}+\int_{0}^{T_{n}} \sum_{j=1}^{k} \lambda_{n j}(t) d t\right) \\
& C_{p 2}=\sum_{i=1}^{N} C_{i}^{p} \\
& C_{d 2}=C_{d i}\left\{\tau_{m} \sum_{n=1}^{N} \int_{0}^{T_{N}} \lambda_{n}(t) d t+(N-1) \tau_{p}+\tau_{r}\right\}
\end{aligned}
$$

In this paper, the complete maintenance strategy and the incomplete maintenance strategy, both based on the competitive Weibull model, are simulated and calculated. The specific process is as follows:

In the case that all the parameters have been obtained, the quantum-genetic algorithm (QGA) mentioned above is used to optimize the two objective functions. First, set the QGA parameters: maximum iteration number $M A X G E N=50$, population size sizepop $=100$, variable binary length lenchrom $=20$. Using the MATLAB programming simulation calculation, the best applicability of the two maintenance strategies of the iterative curve is obtained. Using the MATLAB software to program and simulate the calculation, the iteration curve can be obtained. As shown in Fig. 5, the iteration curves of the incomplete maintenance strategy and the complete maintenance strategy, both based on the competitive Weibull model, are represented by the red curve and the blue curve, respectively. The red curve converges to the global optimum after 18 iterations, i.e., the fitness function value is 1032.50 (i.e., the daily maintenance cost is 1032.50 yuan); the blue curve converges to the global optimum after 24 iterations, i.e., the fitness function value is 920.17 (i.e., the daily maintenance cost is 920.17 yuan). 


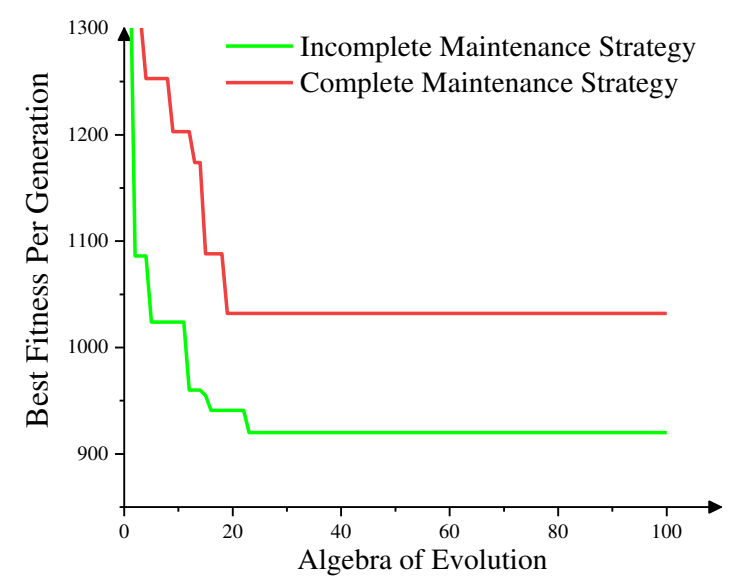

Fig. 5. Iterative Curve of the Quantum-Genetic Algorithm

\subsection{Result analysis}

To prove the superiority of the new maintenance strategy of metro trains based on the competitive Weibull model over the traditional maintenance strategy of metro trains, a comparison is made from three aspects: economy, safety and task. The comparison results are presented in Table 5.

Table 5

Comparison results of the maintenance models.

\begin{tabular}{cccc}
\hline $\begin{array}{c}\text { Maintena } \\
\text { nce model }\end{array}$ & Maintenance interval/day & Availability & $\begin{array}{c}\text { Maintena } \\
\text { nce } \\
\text { cost/(yua } \\
\text { n/day) }\end{array}$ \\
\hline $\begin{array}{c}\text { New } \\
\text { maintenan } \\
\text { ce strategy }\end{array}$ & $62-48-45-42-39-37-35-31-26$ & 0.947 & 920.17 \\
$\begin{array}{c}\text { Complete } \\
\text { maintenan } \\
\text { ce strategy }\end{array}$ & $46-46-46-46-46-46-46-46$ & 0.944 & 1032.50 \\
$\begin{array}{c}\text { Traditional } \\
\text { maintenan } \\
\text { ce strategy }\end{array}$ & $30-30-30-30-30-30-30-30-30-30-$ & 0.936 & \\
\hline
\end{tabular}

The company's current maintenance mode for the metro train door system is equal to interval maintenance, specifically referring to a monthly inspection, and the door system is maintained once a month. A monthly inspection means regular maintenance. If there is any fault during the period, troubleshooting is required. Then, the door is replaced after the last 12 months to complete a maintenance cycle.

This mode is also a mature preventive complete maintenance strategy in the field of maintenance, which is equal to interval maintenance. According to the preventive maintenance threshold, the maintenance interval is selected. In this paper, the maintenance threshold is obtained by optimizing the two objective functions of the highest availability and the lowest maintenance cost by the quantum genetic algorithm. It can be found that each maintenance cycle consists of 8 periodic preventive complete maintenance cycles and that preventive replacement is carried out after one maintenance cycle.

The preventive maintenance strategy of incomplete unequal intervals is adopted in this model. Among them, the core of determining incomplete maintenance is the factor of service life regression and the factor of the increasing failure rate. These two factors are calculated by an empirical formula and historical maintenance data, which are highly accurate. According to the historical fault data and the competitive Weibull model, the reliability of the door system is obtained. Then, the objective function with the highest availability and the lowest maintenance cost is optimized by the quantum genetic algorithm, and the incomplete maintenance threshold is obtained. After a certain number of preventive maintenance cycles of the door system according to the maintenance threshold, preventive replacement of the door system components is carried out.

\section{Table 6}

Proportion of the traditional maintenance strategy cost.

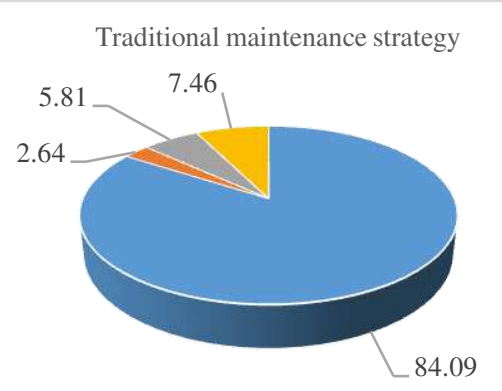

$$
\text { - cost of shutdown - cost of regular maintenance }
$$$$
\text { - cost of minor fault maintenance " cost of replacement }
$$

Table 7

Proportion of the complete maintenance strategy cost.

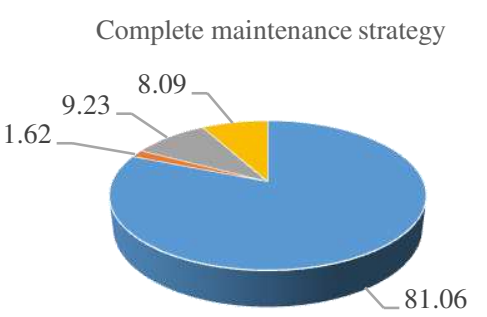

$$
\begin{aligned}
& \text { - cost of shutdown } \\
& \text { - cost of incomplete preventive maintenance } \\
& \text { - cost of minor fault maintenance } \\
& \text { - cost of replacement }
\end{aligned}
$$


Table 8

Proportion of the incomplete maintenance strategy cost

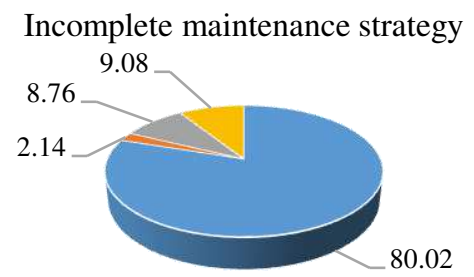

$$
\begin{aligned}
& \text { - cost of shutdown } \\
& \text { " cost of incomplete preventive maintenance } \\
& \text { " cost of minor fault maintenance } \\
& \text { " cost of replacement }
\end{aligned}
$$

Table 6 , table 7 and table 8 are pie charts showing the proportion of the maintenance cost for the traditional maintenance strategy, complete maintenance strategy and incomplete maintenance strategy, respectively. Comparing the three pie charts, we find that the cost of shutdown accounts for more than $80 \%$ of the total maintenance cost. In addition, it can be seen that the cost of shutdown of the traditional maintenance strategy is greater than that of either the complete maintenance strategy or the incomplete maintenance strategy. The cost of shutdown is determined by the number of shutdown days. That is, the number of shutdown days of the traditional maintenance strategy is greater than that of the complete maintenance strategy, while the number of shutdown days of the complete maintenance strategy is greater than that of incomplete maintenance strategy. Therefore, the availability for the maintenance strategy proposed in this paper is also higher than those for the other two maintenance strategies. Second, minor fault maintenance refers to maintenance after a fault occurs during the operation of the train, which may affect the stable operation of the train, so it is necessary to minimize the number of minor fault maintenances. The incomplete maintenance strategy proposed in this paper is incomplete in that the proportion of minor fault repairs is the smallest of the three maintenance strategies. Therefore, compared with the other two kinds of maintenance, the incomplete maintenance strategy presented in this paper has a lower maintenance cost and provides higher availability.

The model proposed in this paper adopts a preventive maintenance strategy, that is, an incomplete strategy with unequal intervals. After a certain number of preventive maintenance cycles of the door system, the door system is preventively replaced. The traditional maintenance strategy is a model that includes replacement after the same period.

(1) According to Table 5, the maintenance cost of the metro train door system based on the competitive Weibull model is 920.17 yuan per day and the total cost of a maintenance cycle is 33261.2 yuan. Compared with the traditional regular maintenance cost of 1120.25 yuan per day, the total cost of a maintenance cycle is 40329 yuan. The cost of maintenance is reduced by $17.86 \%$ by the new maintenance strategy, with 72028.8 yuan saved during one maintenance cycle of the door system. Compared with the daily complete maintenance cost of 1032.50 yuan and the total cost of a single maintenance cycle of 37686.5 yuan, the incomplete maintenance strategy proposed in this paper reduces the cost by $10.88 \%$, with the cost of a single maintenance cycle of 41000.35 yuan. Therefore, from the economic point of view, the new maintenance strategy in this paper is more advantageous than either the traditional maintenance strategy or a complete maintenance strategy.

(2) According to table 5, compared with the availability of the traditional maintenance strategy of 0.936 and the complete maintenance strategy of 0.944 , the availability of the incomplete maintenance strategy is 0.947, representing increases of 0.011 and 0.003 , respectively. Due to the frequent regular maintenance performed, the increase in the shutdown frequency of the traditional maintenance strategy leads to a decrease of its availability. Due to the phenomenon of under-maintenance, the availability of the complete maintenance strategy decreases with the increase in the number of minor fault maintenance cycles. The improvement in availability guarantees that the metro train can better complete its operational tasks. Therefore, from the task aspect, the new maintenance strategy presented in this paper is better than the traditional maintenance strategy.

(3) In addition, the new maintenance strategy presented in this paper is based on the competitive Weibull model, and the parameters of the competitive Weibull model are calculated from the maintenance data of the Nanning metro company. Therefore, the classification of fault data is more in line with the actual situation and the operation status of metro trains. The fault data of metro trains are first classified and processed, and then, the maintenance plan is formulated. This method causes the maintenance strategy to be more reasonable and enhances the scientific nature of the maintenance strategy.

(4) Incomplete maintenance is adopted by the new maintenance strategy in this paper, so the maintenance cycle has unequal intervals, which is more in line with reality. The traditional maintenance strategy is equal interval (monthly) maintenance with maintenance performed once every 30 days. The maintenance threshold is 0.9795 each time, and this is a case of over-maintenance. When the maintenance threshold is chosen to be 0.9795 , frequent shutdown will occur and the shutdown cost accounts for a large part of the total maintenance cost. After calculation, the shutdown cost accounts for $84.099 \%$ of the total maintenance cost, so frequent shutdown will result in a large increase in the maintenance cost. Equal interval maintenance is adopted by the complete maintenance strategy, which uses reliability to determine the maintenance interval. Each preventive maintenance cycle is considered a complete maintenance, that, the repair effect is as good as new. However, the actual engineering effect is not; thus, there will be under-maintenance, which will lead to a large increase in the number of minor fault maintenance cycles, and it 
follows that the maintenance cost will also increase. Based on the competitive Weibull incomplete maintenance model, the maintenance threshold is 0.9187 and the maintenance interval is 62 days- 48 days- 45 days-42 days-39 days-37 days-35 days-31 days-26 days. Compared with traditional maintenance strategy, the number of maintenance cycles will be reduced. At the same time, because the service age reduction factor and the fault rate increase factor are introduced on the premise of ensuring safety, the maintenance interval is more in line with the actual situation, and the maintenance cost is greatly reduced.

\section{Conclusions}

(1) The maintenance strategy presented in this paper is based on the competitive Weibull model. The analysis methods for the fault feature attributes and the fault information sequence have been introduced, so the problems of inaccurate calculation results and impractical maintenance decisions caused by the original single processing of maintenance data for the metro train door system are solved.

(2) Based on the diversity of fault mechanisms, the problem of the limited use of the competitive Weibull model is solved, the method of fuzzy clustering analysis is adopted, and the fault data classification of the metro train door system is completed, which avoids the difficult and heavy workload of fault mechanism detection and analysis.

(3) An incomplete maintenance strategy and unequal interval maintenance based on the competitive Weibull model are adopted in this paper. On the premise of ensuring the safety of the metro train door system, the number of train overhauls and shutdown time are reduced; thus, the maintenance cost of the metro train door system is reduced, and the availability is improved. Therefore, the maintenance strategy improves the security, economy and task completion of the metro train door system.

(4) In this paper, a maintenance mode combining multiple maintenance modes and replacement is adopted to adapt to various failure modes of the mechanical and electrical equipment of the door system, which causes the model to be more robust.

(5) To find the optimal solution of the objective function faster and better, the QGA is used to optimize the process of solving the objective function.

\section{Acknowledgments}

Not applicable.

\section{Authors' contributions}

DH provided guidance for the whole research. JM provided fundamental ideas and all support conditions. XZ took most of the research work. YC provided technical supporting for modeling. $\mathrm{CL}$ and $\mathrm{XY}$ are supervisors who provided opportunity for the cooperative research and offered the original idea for the paper. All authors read and approved the final manuscript.

\section{Authors' Information}

Deqiang He received the Ph.D. degree in mechanical engineering from Chongqing University, China, in 2004. From 2004 to 2007, he worked as a Senior Engineer in CRRC Zhuzhou Institute Co., Ltd. From 2011 to 2012, he was a visiting scholar at the Power Electronics and Motor Drives Laboratory, Michigan State University, USA. He is currently a professor with the School of Mechanical Engineering at Guangxi University. His research fields include fault diagnosis and intelligent maintenance of rail transit train, energy saving operation technology of train, train control and propulsion system.

Xiaozhen Zhang received the B.S. degrees in Mechanical and Electronic from the Guangxi University, China, in 2018. Since 2018, he has been studying as a M. S. candidate in School of Mechanical Engineering at Guangxi University. His research interests include fault diagnosis and intelligent maintenance, reliability analysis of rail transit train.

Yanjun Chen received the Ph.D. degrees in mechanical engineering from Shanghai Jiaotong University, China, in 2016. From 2016 to 2018, he worked as an Engineer in Huawei Technologies Co. Ltd. He is currently an Assistant Professor with the School of Mechanical Engineering at Guangxi University. His research interests include the development of system reliability.

Jian Miao received the Ph.D. degree in mechanical engineering from Chongqing University, China, in 2004. Since 2004, he is a professor with the School of Mechanical Engineering at Guangxi University. His current research fields include fault diagnosis and intelligent maintenance of rail transit train, smart manufacturing.

Congbo Li received the Ph.D. degrees in mechanical engineering from Chongqing University, China, in 2009. He is currently a Professor of Mechanical Engineering at Chongqing University. His research interests include green manufacturing, remanufacturing system, production planning and control, and system modeling and simulation.

Xiaoyang Yao received the M.E. degrees from Huazhong University of Science and Technology, China, in 1987. He is currently a Deputy chief engineer at CRRC Zhuzhou Institute Co., Ltd. His current research fields include fault diagnosis and intelligent maintenance of rail transit train.

\section{Funding}

This work was supported by the National Natural Science Foundation of China [Grant No. 51765006], Natural Science Foundation of Guangxi Province of China [Grant No. 2017GXNSFDA198012], Guangxi Manufacturing Systems and Advanced Manufacturing Technology Key Laboratory Director Fund [Grant No. 19-050-44-S015], Science and Technology Planning Project of Nanning [Grant No. 20193027] and the Innovation Project of Guangxi Graduate Education [Grant No. YCSW2020017]. 


\section{Competing Interests}

The authors declare that they have no competing financial interests

\section{References}

[1] DEQIANG HE, GUANCHENG LU, AND YANJIE YANG. Research on Optimisation of Train Energy-saving Based on Improved Chicken Swarm Optimisation. IEEE ACCESS, 2019,7(1):121675-121684.

[2] MA Liang, Guo Jin, Zhang Xiao-xia. Optimation model and algorithm of preventive maintenance schedule for metro rolling stock. Journal of the China Railway Society, 2016, 38(7):8-14.

[3] Hanlin Liu. Reliability and maintenance modeling for competing risk processes with Weibull inter-arrival shocks. Applied Mathematical Modelling, 2019, 71:194-207.

[4] GUO Jian, XU Zongchang, SUN Hanbing. Opportunistic maintenance threshold optimization of equipment based on proportional hazard model. Computer Integrated Manufacturing Systems, 2017, 23(12):2622-2629.

[5] Malgorzata, Kretowska. Tree-based models for survival data with competing risks. Computer Methods and Programs in Biomedicine, 2018, 159:185-198.

[6] Florence Ducros, Patrick Pamphile. Bayesian estimation of Weibull mixture in heavily censored data setting. Reliability Engineering and System Safety, 2018, 180:453-462.

[7] Ruta Brazauskas, Jennifer Le-Rademacher. Methods for generating paired competing risks data. Computer Methods and Programs in Biomedicine, 2016, 135:199-207.

[8] Debasis Kundu, Debanjan Mitra, Ayon Ganguly. Analysis of left truncated and right censored competing risks data. Computational Statistics \& Data Analysis, 2017, 108:12-26.

[9] Liang Wang. Inference of progressively censored competing risks data from Kumaraswamy distributions. Journal of Computational and Applied Mathematics, 2018, 343:719-736.

[10] Prataviera F, Ortega EMM, Cordeiro GM, Pescim RR, Verssani BAW. A new generalized odd log-logistic flexible Weibull regression model with applications in repairable systems. Reliability Engineering and System Safety, 2018, 176:13-26.

[11] Tomasevicz C L, Asharpoor S. Optimum maintenance policy using semi-Markov decision processes. Electric Power Systems Research, 2009,79(9):23-28.

[12] Phuc D, Voisin, Alexandre, Levrat, Eric, et al. A proactive condition-based maintenance strategy with both perfect and imperfect maintenance actions. Reliability engineering and system safety, 2015,133(1):22-32.

[13] N.Kuboki ,S.Takata. Selecting the Optimum Inspection Method for Preventive Maintenance. Procedia Cire, 2019, 80:512-517.

[14] Ronald M. Martinoda, Olivier Bistorinb, et al. Maintenance policy optimisation for multi-component systems considering degradation of components and imperfect maintenance actions. Computers \& Industrial Engineering, 2018, 122:100-112.

[15] Nguyen D T , Dijoux Y, Fouladirad M. Analytical properties of an imperfect repair model and application in preventive maintenance scheduling. European Journal of Operational Research, 2017, 256(2):439-453.

[16] Shen Guixiang, Gu Dongwei, Zhang Yingzhi, et al. Optimal preventive maintenance interval period of CNC. Journal of Chongqing University, 2012,35(1):7-10.

[17] Wang Lingzhi. Research on Reliability-centered Maintenance Decision and Support System for High-speed Train Equipments .Beijing :BEIJING JIAOTONG UNIVERSTIY, 2011.

[18] R.Mullor, J.Mulero, M.Trottini. A modelling approach to optimal imperfect maintenance of repairable equipment with multiple failure modes. Computers \& Industrial Engineering, 2019, 128:24-31.

[19] A.Khatab, E.H.Aghezzaf. Selective maintenance optimization for series-parallel systems with continuously monitored stochastic degrading components subject to imperfect maintenance. IFAC-Papers On Line, 2016, 49:256-261.

[20] Briš R, Byczanski P. Effective computing algorithm for maintenance optimization of highly reliable system. Reliability Engineering \& System Safety, 2013, 109:77-85.
[21] Laurent Doyen, Olivier Gaudoin, Annamraju Syamsundar. On geometric reduction of age or intensity models for imperfect. Reliability Engineering and System Safety, 2017, 168:40-52.

[22] I. Saha, J.P. Sarkar, U. Maulik. Ensemble based rough fuzzy clustering for categorical data. Knowl-Based Syst, 2015,77:114-127.

[23] J.J. Emilyn, T. Kesavan, et al. A rough set based rational clustering framework for determining correlated genes. Acta Microbiol Immunol, 2016,63(2):185-201.

[24] Deqiang He, Zhou Jiang, Jiyong Chen, Jianren Liu, JianMiao, Abid Shah. Classification of Metro Facilities with Deep Neural Networks. Journal of Advanced Transportation, 2019,2019:1-8.

[25] DEQIANG HE, YANJIE YANG, JIXU ZHOU, YANJUN CHEN. Optimal Control of Metro Energy Conservation Based on Regenerative Braking: A Complex Model Study of Trajectory and Overlap Time. IEEE ACCESS, 2019,7(1):68342-68358.

[26] Indrajit Saha, Jnanendra Prasad Sarkar, Ujjwal Maulik. Integrated Rough Fuzzy Clustering for Categorical data Analysis. Fuzzy Sets and Systems, 2019, 361:1-32.

[27] F. Liang, et al. Recognition algorithm based on improved FCM and rough sets for meibomian gland morphology. Applied Sciences-Basel, 2017,7(2):192.

[28] Pierpaolo D’Urso, Riccardo Massari. Fuzzy clustering of mixed data. Information Sciences, 2019, 505:513-534.

[29] M. Disegna, P. D'Urso, F. Durante. Copula-based fuzzy clustering of spatial time series. Spat Stat, 2017,21:209-225.

[30] P. D’Urso, L.D. Giovanni, M. Disegna, R. Massari. Fuzzy clustering with spatial temporal information. Spat Stat, 2019,30:71-102.

[31] G. Peters, et al. Soft clustering-fuzzy and rough approaches and their extensions and derivatives. International Journal of Approximate Reasoning, 2013,54(2):307-322.

[32] A. Foss, M. Markatou, B. Ray, A. Heching. A semiparametric method for clustering mixed data. Mach. Learn, 2016 ,105 (3): 419-458.

[33] Maryam Gallab, Hafida Bouloiz, et al. Risk Assessment of Maintenance activities using Fuzzy Logic. Procedia Computer Science, 2019, 148:226-235.

[34] R.M, Chandima Ratnayak, K. Antosz. Development of a Risk Matrix and Extending the Risk-based Maintenance Analysis with Fuzzy Logic. Procedia Engineering, 2017, 182:602-610.

[35] Soumava Boral, Ian Howard, et al. An Integrated Approach for Fuzzy Failure Modes and Effects Analysis using Fuzzy AHP and Fuzzy MAIRCA. Engineering Failure Analysis, 2020,21:14-32.

[36] Wang Xingang, Wang Baoyan, Zhang Kuixiao, et al. Sensitivity design for gradual change reliability of mechanical components based on measured information. Transactions of the Chinese Society of Agricultural Engineering, 2012,28(10):65-69.

[37] Gao Limin, Wu Kai, Sun Yu. The Study and Application of the Fuzzy Allocation Method of Reliability for Mechanical System. Mechanical Science and Technology for Aerospace Engineering, 2014,33(12):1798-1802.

[38] Jafarian, Farshid. A Modified Non-Dominated Sorting Genetic Algorithm for Multi-Objective Optimization of Machining Process. Journal of Engineering Science and Technology, 2018,12(13): 4078-4093.

[39] Sajad Mousavia, Fatemeh Afghaha, et al. Use of a quantum genetic algorithm for coalition formation in large-scale UAV networks. Ad Hoc Networks, 2019,87:26-36.

[40] Jyotirmoy Sarkara, Sahadeb Sarkarb. Availability of a periodically inspected system under perfect repair. Journal of Statistical Planning and Inference, 2011, 141(1):610-615. 


\section{Start}

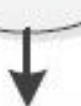

The characteristic attributes of faults set $F$ is established.

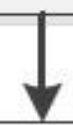

According to the scores of experts, the evaluation value $W$ of the characteristic attributes $F$ for each fault of the system is obtained.

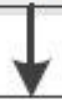

Fuzzy relation matrix $R$ for characteristic attributes of faults $F$ and fault stress $S$.

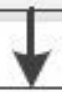

Calculate fault information sequence $B$ based on $R$ and $W$.

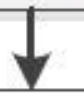

Fault information sequence $B$ is analyzed by fuzzy clustering and fault mechanism similarity is obtained.

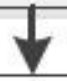

Fault data classification is completed.

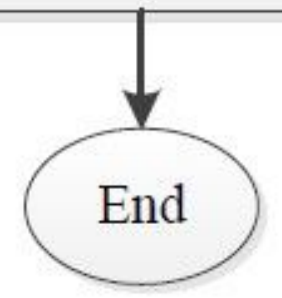

Figure 1

Flow chart for data preprocessing 


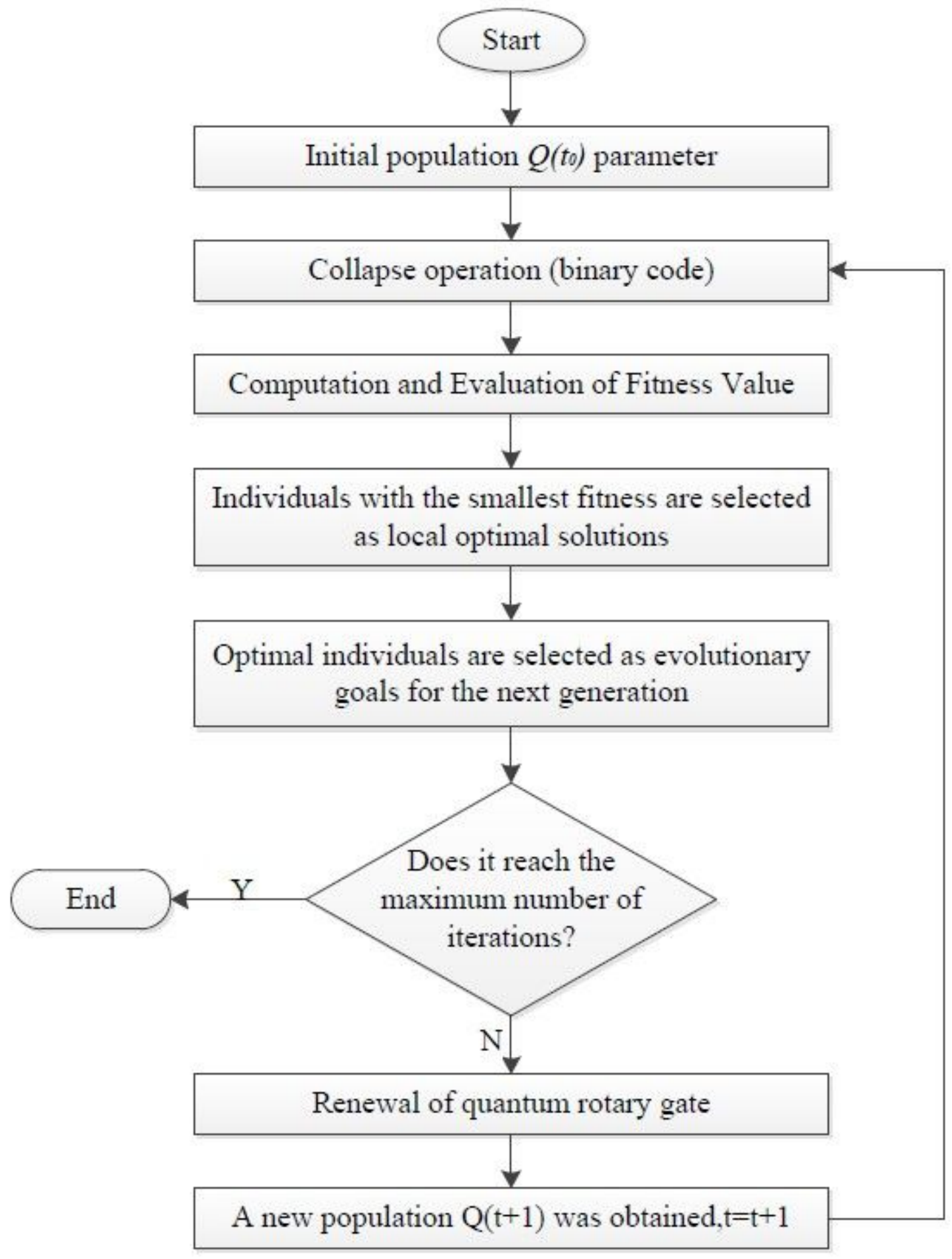

Figure 2

Flow chart for the quantum-genetic algorithm 


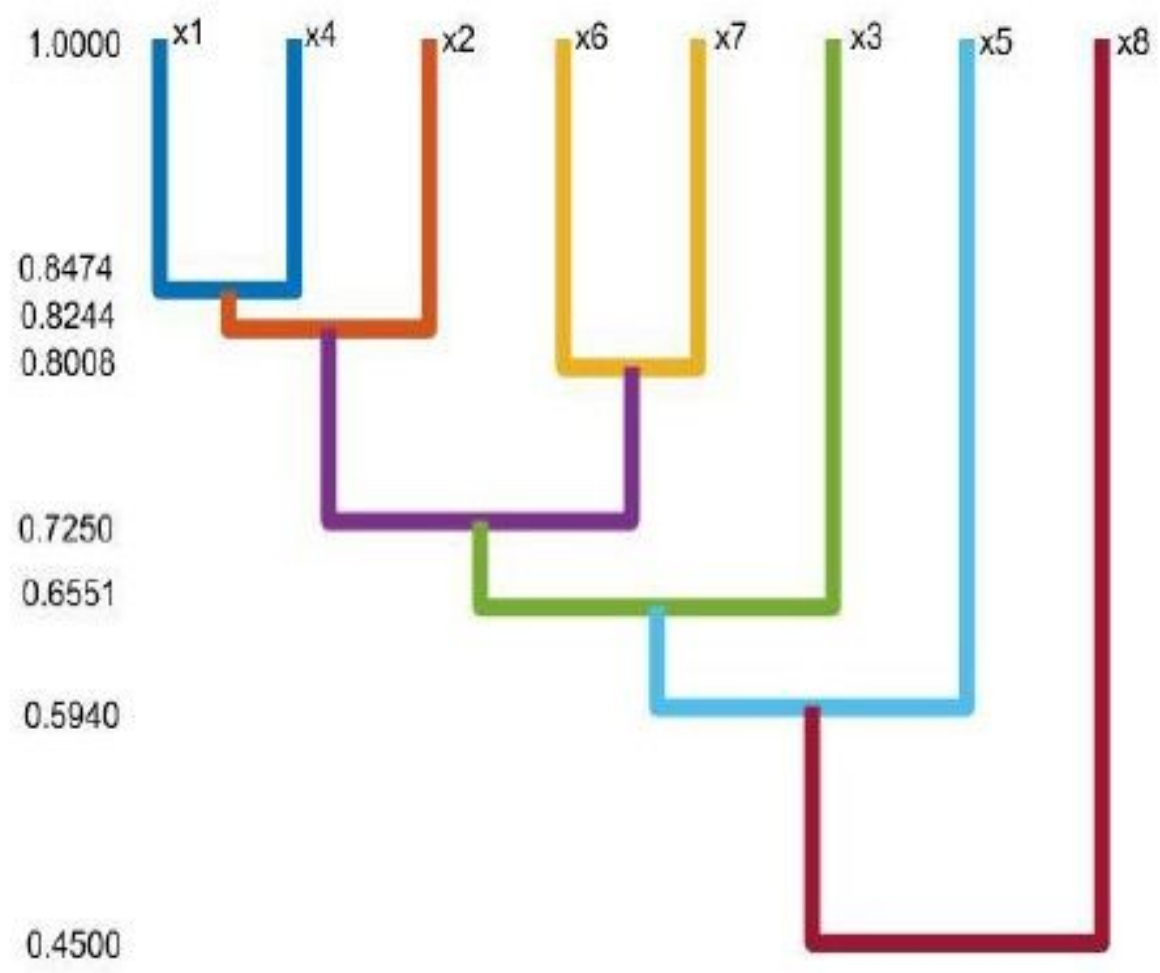

\section{Figure 3}

Cluster analysis diagram

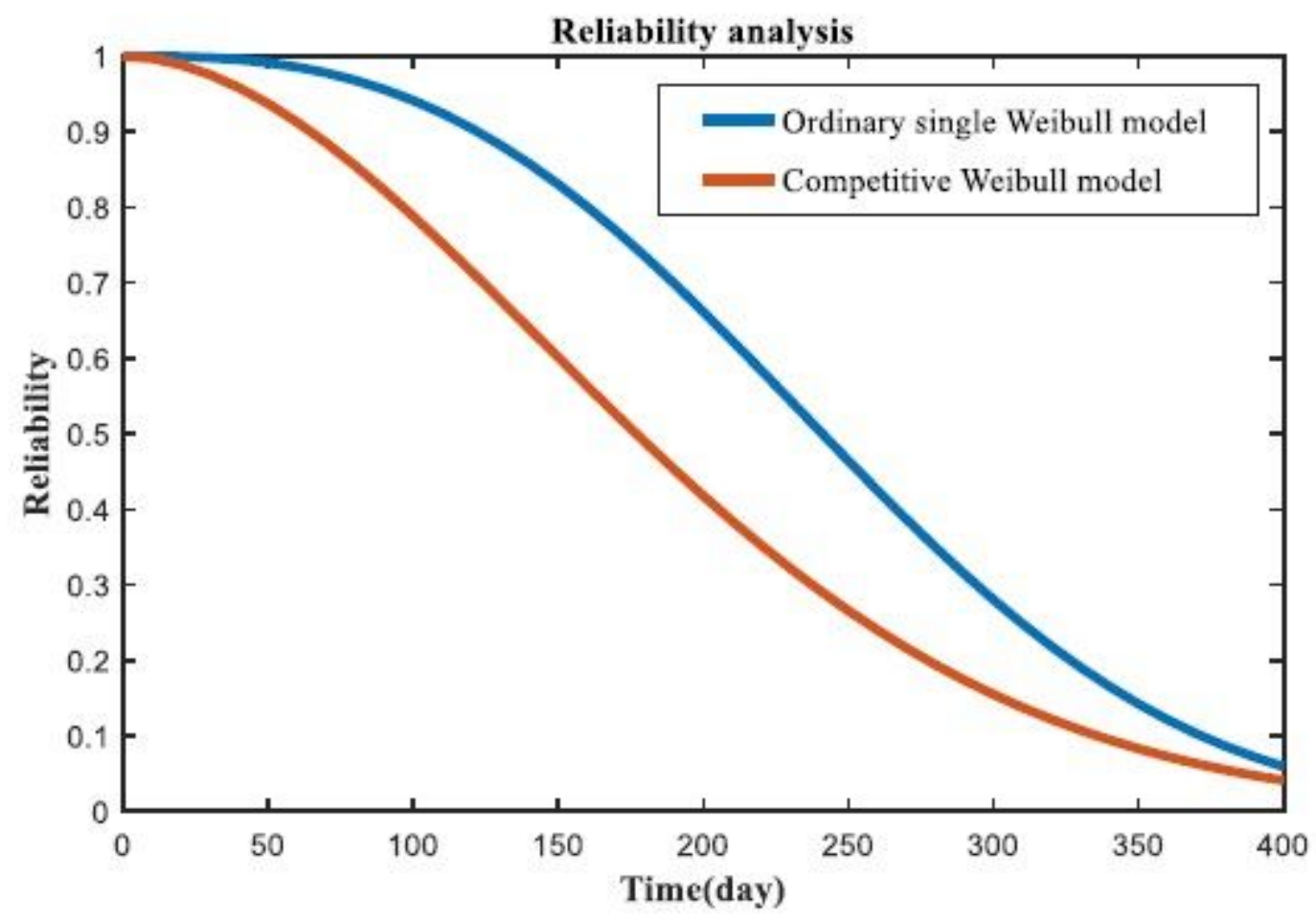

Figure 4 
Reliability Function of the Door System

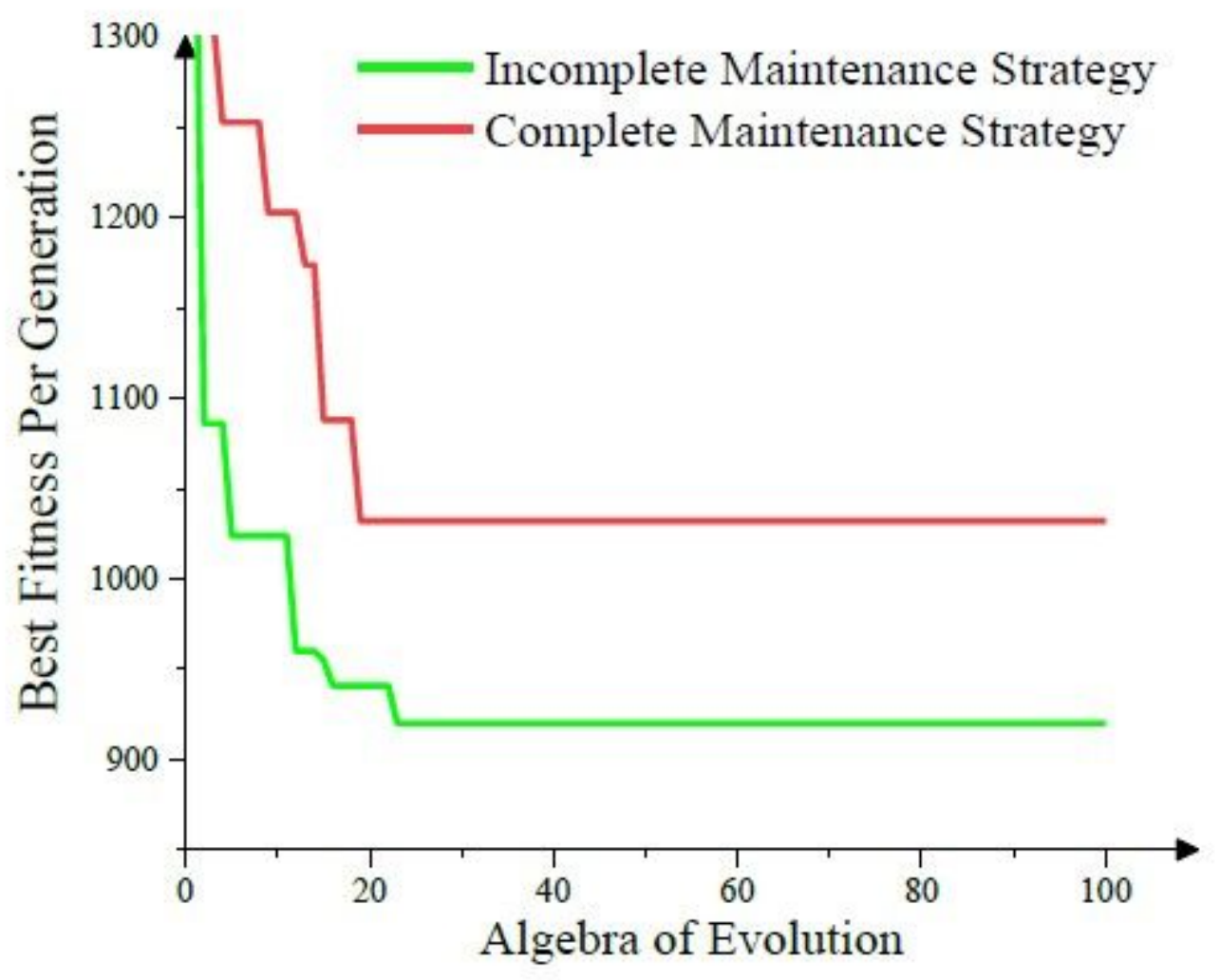

Figure 5

Iterative Curve of the Quantum-Genetic Algorithm 